ARTICLE

\title{
PAF-Wnt signaling-induced cell plasticity is required for maintenance of breast cancer cell stemness
}

Xin Wang ${ }^{1, \star}$, Youn-Sang Jung ${ }^{1, \star}$, Sohee Jun ${ }^{1, \star}$, Sunhye Lee ${ }^{1}$, Wenqi Wang ${ }^{1}$, Andrea Schneider ${ }^{1}$, Young Sun Oh', Steven H. Lin ${ }^{1}$, Bum-Joon Park², Junjie Chen ${ }^{1}$, Khandan Keyomarsi ${ }^{1} \&$ Jae-II Park ${ }^{1,3,4}$

Cancer stem cells (CSCs) contribute to tumour heterogeneity, therapy resistance and metastasis. However, the regulatory mechanisms of cancer cell stemness remain elusive. Here we identify PCNA-associated factor (PAF) as a key molecule that controls cancer cell stemness. PAF is highly expressed in breast cancer cells but not in mammary epithelial cells (MECs). In MECs, ectopic expression of PAF induces anchorage-independent cell growth and breast CSC marker expression. In mouse models, conditional PAF expression induces mammary ductal hyperplasia. Moreover, PAF expression endows MECs with a self-renewing capacity and cell heterogeneity generation via Wnt signalling. Conversely, ablation of endogenous PAF induces the loss of breast cancer cell stemness. Further cancer drug repurposing approaches reveal that NVP-AUY922 downregulates PAF and decreases breast cancer cell stemness. Our results unveil an unsuspected role of the PAF-Wnt signalling axis in modulating cell plasticity, which is required for the maintenance of breast cancer cell stemness.

\footnotetext{
${ }^{1}$ Department of Experimental Radiation Oncology, University of Texas MD Anderson Cancer Center, 6565 MD Anderson Boulevard, Z6.6034, Unit 1052, Houston, Texas 77030, USA. ${ }^{2}$ Department of Molecular Biology, Pusan National University, Busan 609-735, Korea. ${ }^{3}$ Program in Genes and Development, University of Texas MD Anderson Cancer Center, Houston, Texas 77030, USA. ${ }^{4}$ Graduate School of Biomedical Sciences, University of Texas Health Science Center and MD Anderson Cancer Center, Houston, Texas 77030, USA. * These authors contributed equally to this work. Correspondence and requests for materials should be addressed to J.-I.P. (email: jaeil@mdanderson.org).
} 
S tem cells (SCs) are characterized by their abilities to self-renew and to constitutively or conditionally differentiate into committed cells ${ }^{1}$. Cellular heterogeneity driven by SCs is tightly controlled by developmental signalling pathways during development and regeneration. In recent times, an emerging concept, 'cell plasticity', has challenged the paradigm that SCs are the source of cell heterogeneity. In the cell plasticity model, cells bypass the lineage barrier and give rise to functionally and phenotypically different cells. For instance, transplanted bone marrow cells can differentiate into muscle cells $^{2}$. Similarly, cells isolated from the brain and muscle are able to reconstitute the haematopoietic system ${ }^{3}$. The expression of lineage-specific transcription factors leads to the development of early progenitor cells that can give rise to differentiated cells $s^{4,5}$. Moreover, fibroblasts can be directly reprogrammed into committed differentiated cells ${ }^{6-8}$. Cellular dedifferentiation and transdifferentiation processes occur not only in these experimental settings but also during tissue regeneration. For example, on pancreatic tissue injury, pancreatic $\beta$ cells are generated via self-duplication ${ }^{9}$ or transdifferentiation of $\alpha$ cells ${ }^{10}$. In addition, exocrine cells can be reprogrammed to become $\beta$ cells $^{11}$. Despite the biologic and pathologic significance of cell plasticity in tissue homeostasis and cancer, its underlying regulatory mechanism remains elusive.

Cancer SCs (CSCs) are regarded as a source of heterogeneous tumour cells and are responsible for tumour initiation, metastasis, recurrence and therapy resistance ${ }^{12,13}$. Although CSCs are somewhat similar to tissue SCs in that they are self-renewing, rare cell populations, their origin is still uncertain. Accumulating evidence indicates that CSCs originate from SCs, progenitor cells or differentiated cells ${ }^{14}$. However, these models have not been experimentally tested. It is possible that differentiated cells can be converted into progenitor cells or CSCs during tumorigenesis, similar to the cell dedifferentiation that has been observed in haematopoietic systems ${ }^{4,5}$. In this study, we found that the proliferating cell nuclear antigen-associated factor $(P A F)$-Wnt signalling axis converts normal epithelial cells into CSC-like (CSL) cells.

PAF (also known as p15/KIAA0101/NS5ATP9/OEACT-1) was initially identified as a proliferating cell nuclear antigeninteracting protein ${ }^{15}$. PAF modulates translesion DNA synthesis, a DNA bypass process, by facilitating the switch of the translesion DNA synthesis polymerase ${ }^{16}$. In recent times, we found that PAF, as a co-factor of $\beta$-catenin transcriptional complex, positively modulates Wnt signalling ${ }^{17}$. In this study, our results revealed that PAF is highly expressed in breast cancer cells and plays key roles in inducing mammary epithelial cell (MEC) plasticity and maintaining breast cancer cell stemness.

\section{Results}

Expression of PAF in breast cancer cells. To identify the genes that play key roles in mammary tumorigenesis, we initially performed in silico analyses of publicly available breast cancer gene expression data sets (www.oncomine.org). We identified several genes that were highly expressed in breast cancer cells but not in normal breast tissues; $P A F$ expression was remarkably upregulated in human breast cancer cells (Fig. 1a). To validate $P A F$ upregulation in breast cancer, we performed immunohistochemical analyses using human breast cancer tissue microarrays. PAF expression was not detectable in normal MECs but was strongly expressed in the nuclei of invasive lobular, glandular and ductal adenocarcinoma cells (Fig. 1b). Consistently, PAF expression was significantly elevated in breast cancer cell lines but barely expressed in non-tumorigenic 76NF2V and hMLE human MECs (Fig. 1c). Of note is that luminal B and basal breast cancer cell lines show the higher expression of PAF, compared with luminal A breast cancer cell lines (Fig. 1c). In addition, a Kaplan-Meier analysis showed that high levels of PAF expression were strongly associated with poor prognosis in a

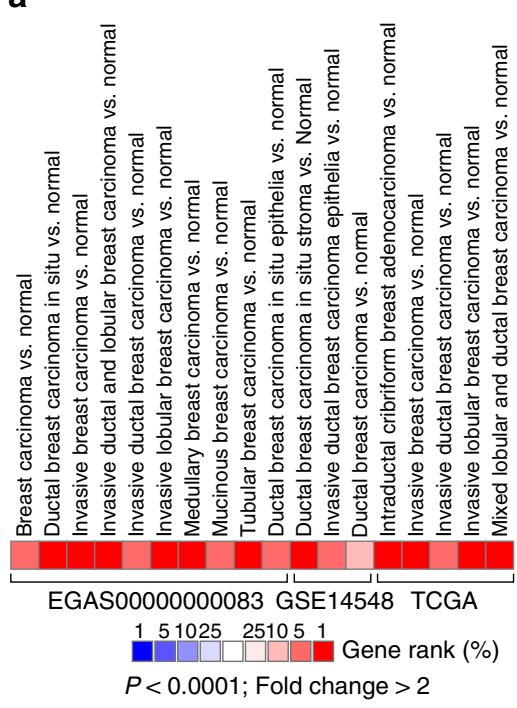

b

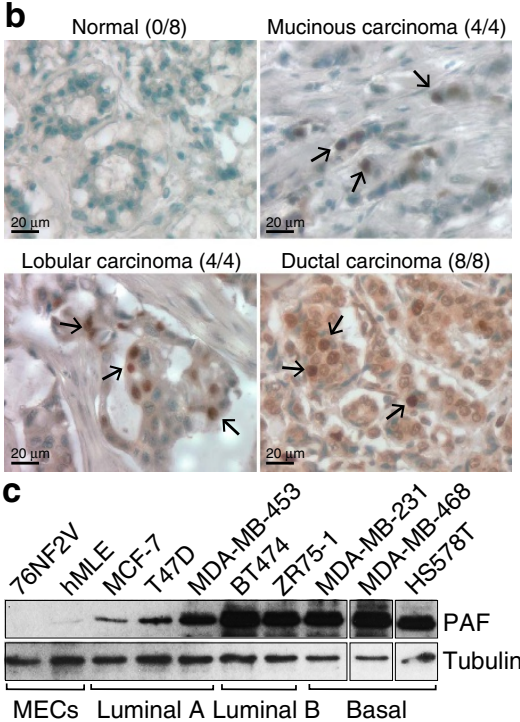

d

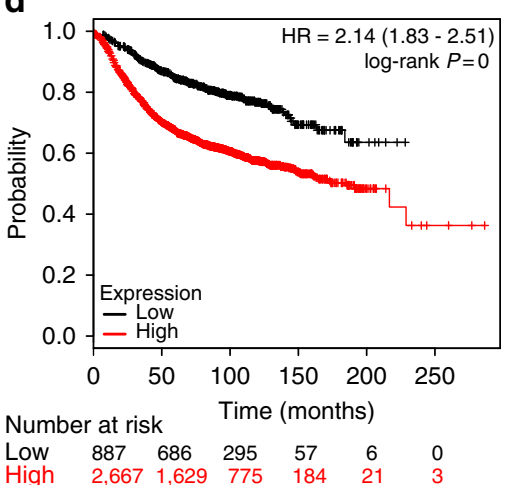

Figure 1 | PAF expression in breast cancer cells. (a) In silico analysis of PAF expression in human breast cancer. Expression of $P A F$ was analysed using publicly available Oncomine database (www.oncomine.org; $P<0.0001$; fold change $>2$; Student's $t$-test). (b) Expression of PAF in breast cancer. Breast cancer tissue microarray was immunostained for PAF using anti-PAF antibody and 3,3'-diaminobenzidine (DAB; brown). Haematoxylin was used for nuclear counterstaining (blue). Arrows: nuclear expression of PAF in breast cancer cells. Numbers in parentheses indicate number of PAF-positive samples out of number of total samples. Scale bars, $20 \mu \mathrm{m}$. (c) Expression of PAF in breast cancer cell lines. Human MECs and breast cancer cell lines were analysed for PAF expression using immunoblotting (IB) assays. (d) Survival graphs of breast cancer based on PAF expression. Using publicly available database (KM plotter; www.kmplot.com), relapse-free survival curves were analysed by PAF expression. A total of 3,554 patients; probe $=202503 \_s \_a t ; ~ P=0$. Probe 211713_x_at also showed the similar results $\left(P=1.2 \times 10^{-5}\right)$. Log-rank $P$-values were calculated in kmplot database. 
breast cancer (Fig. 1d and Supplementary Fig. 1). These results suggest that PAF expression is remarkably elevated in breast cancer cells.

Acquisition of transforming activity by PAF. Owing to the significant upregulation of $P A F$ in breast cancer cells (Fig. 1), we hypothesized that PAF plays pro-tumorigenic roles in breast cancer. To test this, we assessed the effects of PAF expression on cellular transformation by evaluating the anchorage-independent growth of 76NF2V MECs, which do not express PAF (Fig. 1c). Similar to other MECs, 76NF2V-vector (control) cells did not grow in semisolid matrices. However, $76 \mathrm{NF} 2 \mathrm{~V}$ cells that stably expressed PAF (76NF2V-PAF) exhibited anchorage-independent growth (Fig. 2a,b). To further characterize the tumorigenic roles of PAF, we used a three-dimensional cell culture system. We plated an equal number (2,000 cells) of each group of cells (76NF2V-vector and -PAF) on Matrigel and cultured the cells for
12 days. 76NF2V-vector cells developed uniform round spheres. However, 76NF2V-PAF cells exhibited a loss of epithelial cell polarity and dendritic extension, as also shown in MDA-MB-231 breast cancer cells that served as a positive control (Fig. 2c).

Owing to the loss of epithelial cell polarity by PAF ectopic expression (see Fig. 2c), we next determined whether PAF expression induced epithelial-mesenchymal transition (EMT). Whereas $76 \mathrm{NF} 2 \mathrm{~V}$-vector cells exhibited the typical epithelial cell morphological characteristics ${ }^{18}, 76 \mathrm{NF} 2 \mathrm{~V}-\mathrm{PAF}$ cells were heterogeneous (epithelial and mesenchymal) (Fig. 2d). To further characterize PAF-induced changes in cell morphological characteristics, we separated 76NF2V-PAF mesenchymal cells from epithelial cells by mild trypsinization. Each group of cells was evaluated according to their cellular morphological characteristics in the cell culture. Interestingly, 76NF2V-PAF epithelial cells continuously gave rise to both epithelial and mesenchymal cells, whereas mesenchymal cells generated only mesenchymal cells (Fig. 2d), accompanied by upregulated a
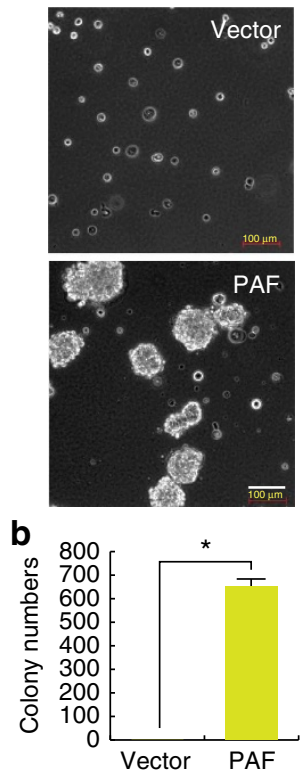

C
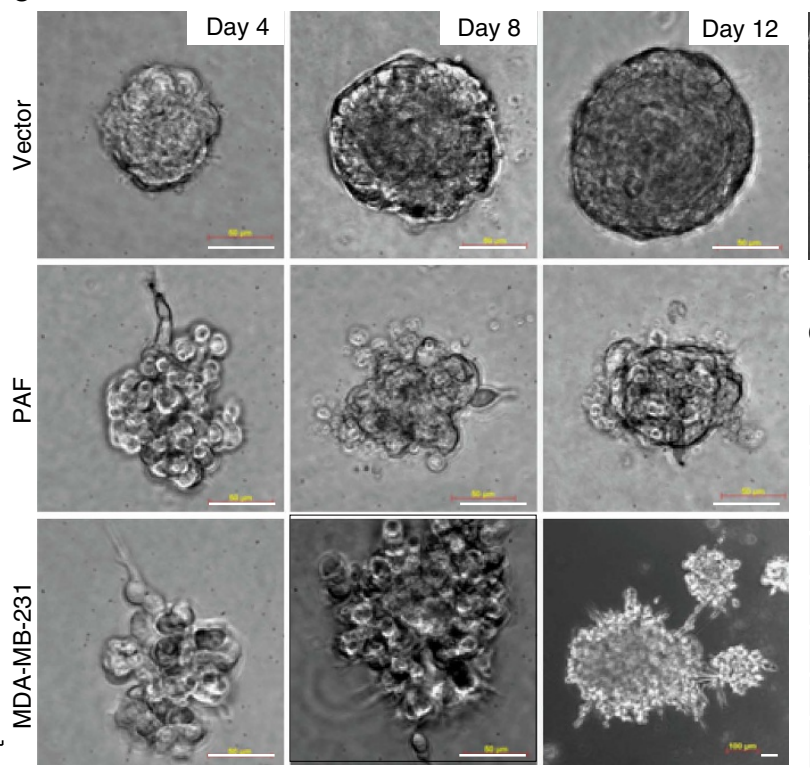

d

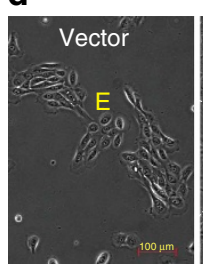

e
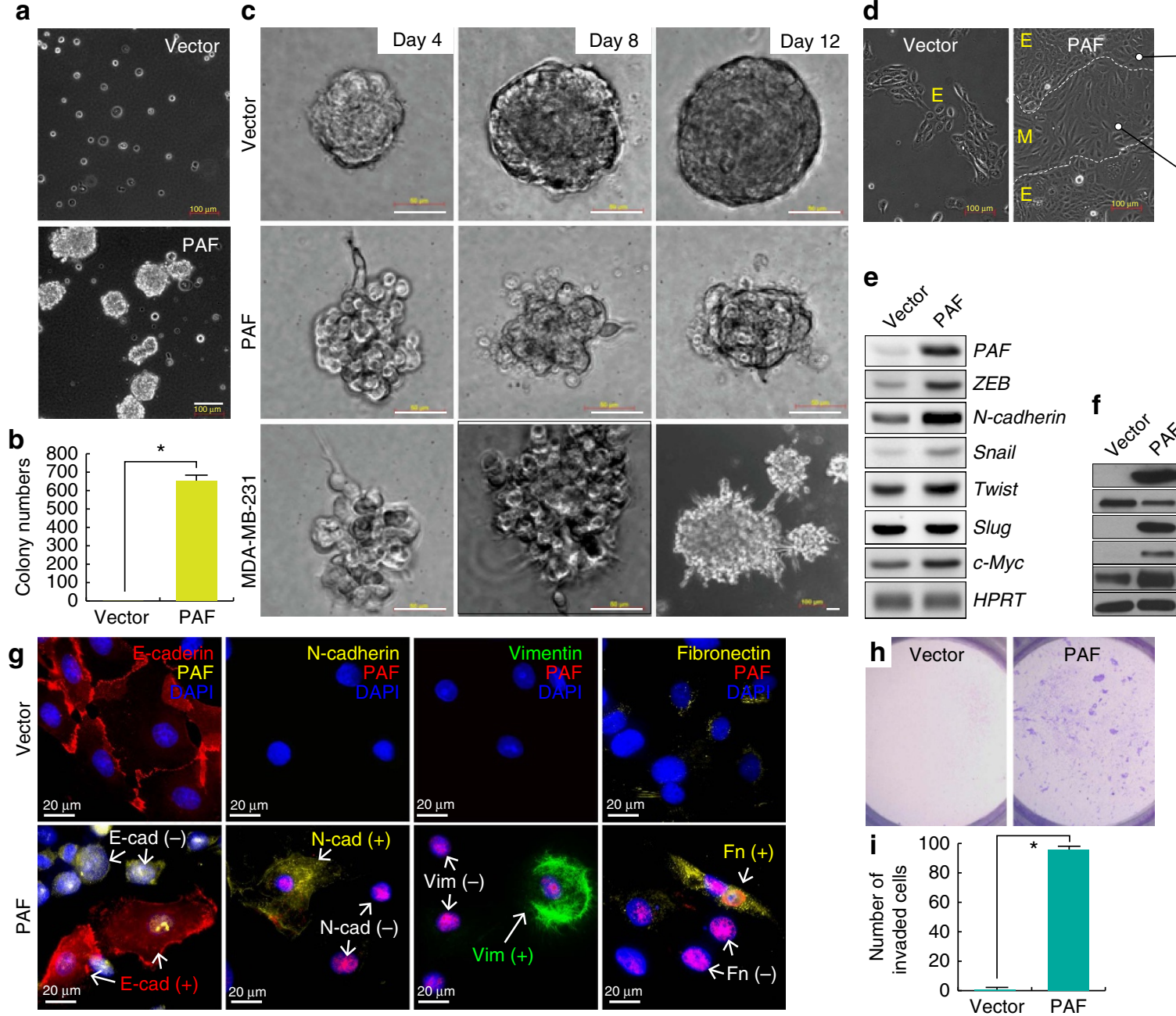

$20 \mu$

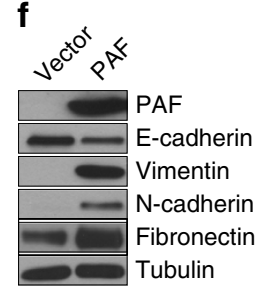

Figure 2 | In vitro tumorigenic function of PAF. (a,b) Anchorage-independent growth of PAF-expressing MECs. Soft agar clonogenic assays were performed using 76NF2V-vector (control) or -PAF MECs. Each group of cells was grown in semisolid matrices (soft agar) for 3 weeks and analysed. (a) Phase-contrast images. (b) The number of colonies was quantified using colony counting. Student's $t$-test; error bars $=\mathrm{s}$.e.m. Scale bars, $100 \mu \mathrm{m}$. (c) PAF-induced transformation of MECs. 76NF2V-vector, -PAF and MDA-MB-231 cells were cultured in three-dimensional Matrigel. Phase-contrast images of spheroid formation of each group of cells. MBA-MB-231 cells served as a positive control. Scale bars, $50 \mu$ m. (d) EMT by PAF. By light trypsinization, epithelial cell-like cells (e) and mesenchymal cell-like cells ( $\mathbf{m}$ ) were separated and cultured subsequently. It is noteworthy that e cells generate $\mathrm{m}$ cells but not vice versa. Scale bars, $100 \mu \mathrm{m}$. (e-g) Upregulation of EMT-related genes. 76NF2V cells (vector versus PAF) were analysed for reverse transcriptase-PCR (RT-PCR) (e), IB (f) and immunofluorescent staining (g). Scale bars, $20 \mu \mathrm{m}$. (h,i) Increased cell invasion by PAF. 76NF2V cells (vector versus PAF) were analysed for cell invasion assays. Images of cell migration (h); quantitative analysis (i). Student's $t$-test; error bars $=$ s.e.m. ${ }^{\star} P<0.05 ; N>3$. 
expression of mesenchymal markers and increased cell invasion (Fig. 2e-i). These results suggest that PAF plays tumorigenic roles, represented by anchorage-independent cell growth and EMT.

Mammary ductal hyperplasia by PAF. Next, we determined the physiologic roles of PAF in vivo by mimicking a condition of upregulated PAF in breast cancer. We used genetically engineered mouse models with a tetracycline-inducible gene expression system, as described previously ${ }^{17,19}$. For conditional expression of PAF, a $P A F$-inducible strain $(P A F)$ was bred with
MMTV-rtTA or Rosa26-rtTA strains. Next, MMTV-rtTA:iPAF or Rosa26-rtTA:iPAF compound mice were treated with doxycycline, an analogue of tetracycline, which leads to the induction of PAF expression (Fig. 3a). After 4 weeks of doxycycline treatment, we assessed the development of the mammary ducts of the iPAF, MMTV-rtTA, iPAF:MMTV-rtTA, $i P A F+$ doxycycline and $M M T V-r t T A+$ doxycycline strains (control groups), and the MMTV-rtTA:iPAF+doxycycline compound strain (experimental group) (Fig. 3b). During development, the mammary ducts elongate and bifurcate, which is mainly driven by the activation of mammary SCs located in the terminal end buds (TEBs) (Fig. 3c). Surprisingly, mice that a

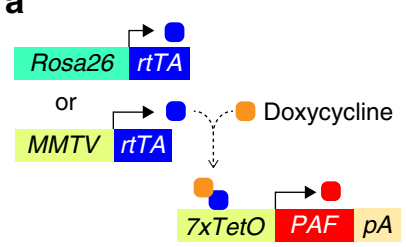

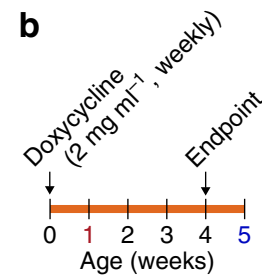

d
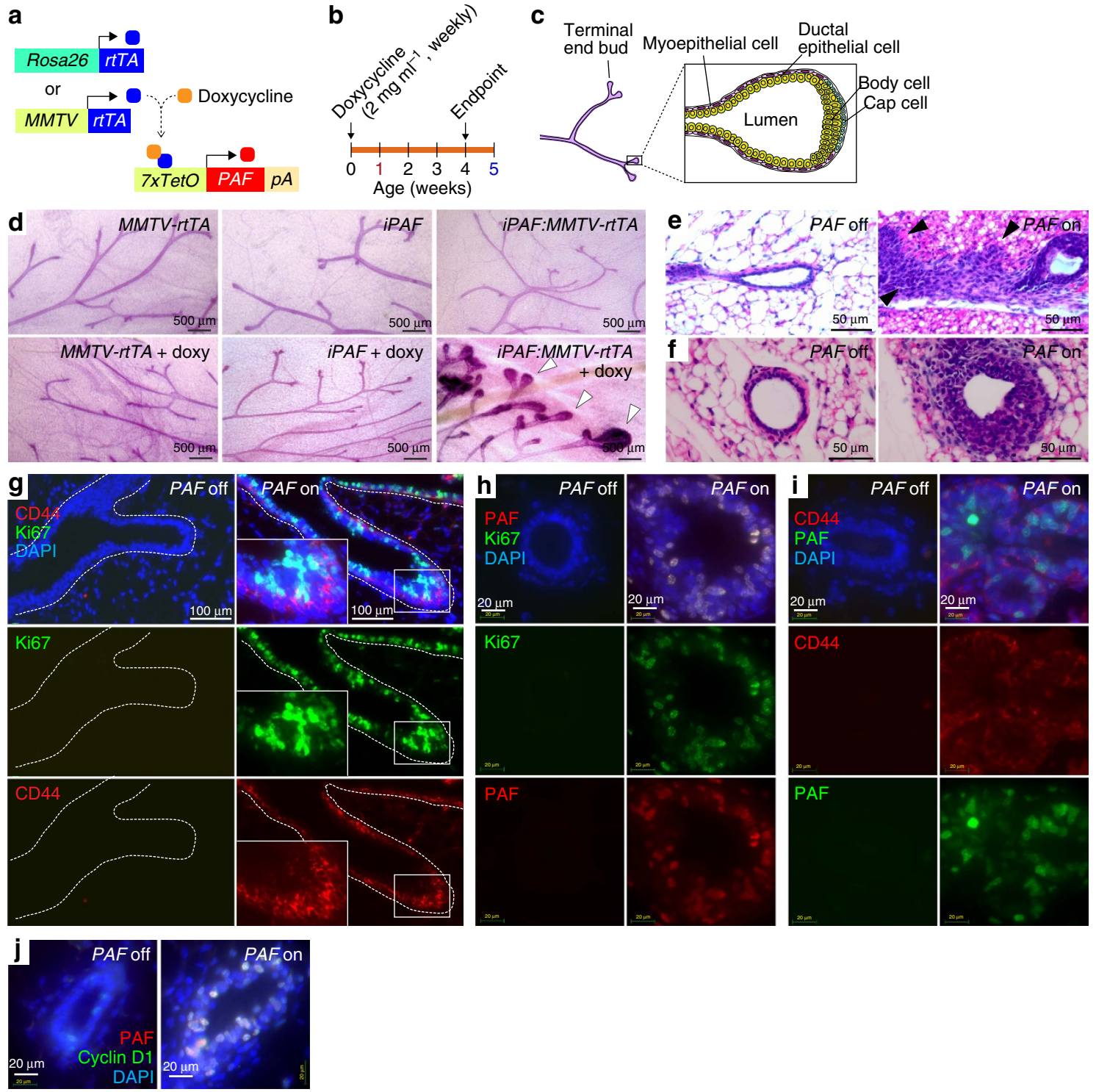

Figure 3 | Mammary ductal hyperplasia by PAF conditional expression. (a) Schematic diagram of PAF-inducible mouse models. For MEC-specific induction of PAF, MMTV-rtTA driver was bred with IPAF strain. On doxycycline treatment in drinking water, activated rtTA binds to TetO and transactivates PAF expression in MECs. Alternatively, Rosa26-rtTA strain was used. (b) Doxycycline administration strategies. Doxycycline was administrated in drinking water (5\% sucrose) for each time point. (c) Illustration of mammary duct structure. (d-f) Ductal hyperplasia by PAF conditional expression. MMTV-rtTA:iPAF (experimental group) or MMTV-rtTA (control) mice were treated with doxycycline ( $2 \mathrm{mg} \mathrm{ml}^{-1}$ ) for 30 days after weaning. Longitudinal (d) or transverse (e) sectioned mammary glands were stained with haematoxylin and eosin. Arrowheads (white): hyperplastic TEBs; arrowheads (black): infiltrated ductal epithelial cells (f). Hyperproliferation of ductal epithelial cells by PAF. Ki67 immunostaining of longitudinal section. Scale bars, $500 \mu \mathrm{m}$ (d); $50 \mu \mathrm{m}(\mathbf{e}, \mathbf{f})$. ( $\mathbf{g}-\mathbf{i})$ Upregulation of CD44 by conditional expression of PAF. Ki67 (green) and CD44 (red) immunostaining of mammary ducts. To exclude indirect effects of PAF expression on cell proliferation, doxycycline was administrated for 7 days instead of 30 days. Scale bars, $100 \mu \mathrm{m}$ ( $\mathbf{g}$ ); $20 \mu \mathrm{m}$ $(\mathbf{h}, \mathbf{i})$. (j) Upregulation of Cyclin D1 by conditional expression of PAF. Doxycycline treated for 7 days. Scale bars, $20 \mu \mathrm{m}$. 
conditionally expressed $P A F$ displayed ductal hyperplasia, which manifested with enlarged TEBs, increased ductal bifurcation, side branching and thickened ducts (Fig. 3d). A microscopic analysis further showed that the mammary ductal epithelium was remarkably hyperplastic in MMTV-rtTA:iPAF mice, whereas the $i P A F$ only (control) mice displayed a single layer of ductal epithelium (Figs 3e,f). Similarly, Rosa26-rtTA driver-induced PAF expression also induces mammary ductal hyperplasia (Supplementary Fig. 2).

To exclude any indirect effects of the long-term induction of $P A F$, we also examined the mammary tissues of mice treated with doxycycline for 7 days. The short-term administration (7 days) of doxycycline was sufficient to induce hyperproliferation of ductal epithelial cells, as displayed by Ki67-positive cells in both luminal and basal epithelial (BE) cells. However, the mammary tissues of control mice exhibited Ki67-positive cells only in TEBs (Fig. 3g,h). Previously, we found that PAF hyperactivates Wnt signalling as a co-factor of the $\beta$-catenin transcription complex ${ }^{17}$. Thus, we determined whether PAF conditional expression activates Wnt signalling by assessing the expression of $C D 44$, a $\beta$-catenin target gene ${ }^{20}$. We found that CD44 was strongly upregulated in the entire mammary epithelium of PAF-induced mice (doxycycline for 7 days) but was weakly expressed in the TEBs of control mice (Fig. 3g,i). Additional $\beta$-catenin target gene, Cyclin D1, was significantly upregulated by PAF conditional expression (Fig. 3j). Consistently, we observed that conditional expression of PAF upregulates $\beta$-catenin protein ( 7 days of doxycycline treatment) and induces the nuclear translocation of $\beta$-catenin (30 days of doxycycline) (Supplementary Fig. 3). These results suggest that the conditional expression of PAF induces mammary ductal hyperplasia with activation of Wnt signalling.

We induced PAF expression in mammary epithelium for a long-term analysis. The conditional expression of $P A F$ for up to 8 months did not result in a mammary tumour (data not shown), suggesting that PAF per se is not sufficient to initiate mammary tumorigenesis. Next, we determined whether additional factors (inactivation of $\mathrm{p} 53$ or $\mathrm{pRb}$ ) are required for PAF-induced tumour development. We performed xenograft transplantation assays using various $76 \mathrm{NF} 2 \mathrm{~V}$ MECs expressing E6, E7 or TERT. We subcutaneously injected MECs that stably expressed PAF into nude mice. 76NF2V and HMLE did not form tumours ex vivo ${ }^{21}$. However, 76NE6 or 76NE6/TERT cells that stably expressed PAF developed the tumours in immunocompromised mice (Supplementary Fig. 4). Of note, p53 was inactivated by E6 protein in 76NE6 and 76NE6/TERT MECs. Thus, these results indicate that in the setting of $\mathrm{p} 53$ inactivation, PAF contributes to mammary tumour initiation. Our results suggest that the conditional expression of PAF induces mammary ductal hyperplasia and initiates tumour development in the setting of p53 inactivation.

Generation of cancer SC-like cells by PAF-Wnt axis. CSCs are a rare cell population that replenishes the entire tumour; they also play essential roles in tumorigenesis and metastasis ${ }^{12,13}$. Our results show that (a) PAF is specifically expressed in breast cancer cells (Fig. 1b) and (b) PAF expression induces the cellular transformation of MECs (Fig. 2a-c) with Wnt signalling activation (Fig. 3g). In addition, the results of our previous study showed that PAF expression is associated with cell stemness in embryonic and intestinal $\mathrm{SCs}^{17}$. These results led us to hypothesize that PAF expression is associated with the development or maintenance of CSCs. Therefore, to assess the impact of PAF on the self-renewal capacity of MECs, we performed mammosphere assays. 76NF2 V-PAF cells formed remarkable mammospheres, whereas $76 \mathrm{NF} 2 \mathrm{~V}$-vector control cells did not develop mammospheres (Fig. 4a). In addition, only
76NF2V-PAF cells formed the successive mammospheres in the secondary and tertiary cultures by single-cell dissociation (Fig. 4b). Similarly, hMLE stably expressing PAF displays the increase in mammosphere formation (Supplementary Fig. 5).

Next, we examined the expression of breast CSC-associated markers in $76 \mathrm{NF} 2 \mathrm{~V}$ cells. Immunofluorescence (IF) staining showed that CD44 was upregulated in 76NF2V-PAF, while the expression of EpCAM and CD24 was heterogeneous and slightly downregulated by PAF expression (Fig. 4c). To better analyse the expression of breast CSC markers (CD24 $4^{\text {low }}$ and CD44 $\left.4^{\text {high }}\right)^{22}$, we used fluorescence-activated cell sorting (FACS). 76NF2V-vector cells exhibited CD24high and CD44 low expression, indicating their luminal epithelial (LE) properties ${ }^{23}$. However, 76NF2V-PAF cells displayed CD24 $4^{\text {low }}$ and CD44 $4^{\text {high }}$ expression (Fig. 4d). Aldehyde dehydrogenase (ALDH), another breast CSC marker ${ }^{24}$, was significantly upregulated in $76 \mathrm{NF} 2 \mathrm{~V}-\mathrm{PAF}$ cells, similar to MDA-MB-231, which served as a positive control (Fig. 4e). These results suggest that PAF expression converts MECs into breast CSL cells.

Having found that PAF expression upregulates breast CSC markers (see Fig. 4c-e), we hypothesized that it induces the cell plasticity that converts MECs into breast CSL cells. We first determined whether PAF-expressing MECs generate cellular heterogeneity. On the basis of the differential expression of CD24, CD44 and EpCAM cell surface markers ${ }^{25}$, we sorted MECs into LE cells (CD44 $4^{\text {low }}$ CD2 $4^{\text {high }}$ EpCAM $^{\text {high }}$ ), BE cells $\left(\mathrm{CD} 44^{\text {high }} \mathrm{CD} 24^{\text {negative }} \mathrm{EpCAM}{ }^{\text {negative }}\right)$ and breast $\mathrm{CSL}$ cells $\left(\mathrm{CD} 44^{\text {high }} \mathrm{CD} 24^{\text {negative }} \mathrm{EpCAM}^{\text {low }}\right.$ ) (Fig. 4f,g). $76 \mathrm{NF} 2 \mathrm{~V}$-vector control cells exhibited LE characteristics (93\%), confirming their luminal origin ${ }^{23}$. However, $76 \mathrm{NF} 2 \mathrm{~V}$-PAF cells gave rise to LE, BE and CSL cells (Fig. 4h). Next, we determined whether the CSL cells generated by PAF successively give rise to cellular heterogeneity. We sorted 76NF2V-PAF cells into LE, BE and CSL cells using FACS and cultured each group of cells for 6 days. We then reanalysed each cell population on the basis of CD24, CD44 and EpCAM expression. The sorted BE and LE cells reproduced $\mathrm{BE}$ and LE, respectively. Of note, $\mathrm{LE}$ cells also partially generated some BE cells (Fig. 4h and Supplementary Fig. 6), which recapitulates EMT induction by PAF (Fig. 2d-i). Interestingly, we observed that CSL cells gave rise to LE, BE and CSL cell populations (Fig. 4h and Supplementary Fig. 6). The phase-contrast images also showed that the sorted CLS cells generated various cells with different morphological characteristics after 6 days of culture (Fig. 4i), consistent with IF staining results showing PAF-induced heterogeneous expression of CD44, EpCAM and EMT-related genes (Figs 2g and 4c). These results suggest that CSL cells induced by PAF generates cellular heterogeneity. In addition, owing to differential capability of PAF expression in generating CSCs, we asked whether the different level of PAF expression determines each cell fate, by assessing PAF expression. However, we found that there is no significant difference in $P A F$ transcription among those three cell populations (Supplementary Fig. 7), implying that posttranslational modification of PAF might be involved in modulating PAF activity.

Given that PAF activates the $\beta$-catenin transcriptional complex and promotes Wnt target gene transcription ${ }^{17}$, we determined whether it generates CSL cells via $W n t / \beta$-catenin signalling. Ectopic expression of PAF remarkably upregulated AXIN2, a well-established $\beta$-catenin target gene ${ }^{26}$, in $76 \mathrm{NF} 2 \mathrm{~V}-\mathrm{PAF}$ cells (Fig. 4j), which was suppressed by iCRT14 treatment (Fig. 4k), recapitulating that PAF activates $\mathrm{Wnt} / \beta$-catenin signalling in mammary epithelium (see Fig. 3g). We next determined whether PAF-induced CSL cell generation is inhibited by iCRT14, an inhibitor of $\beta$-catenin-T-cell factor (TCF) binding ${ }^{27}$. iCRT14-treated 76NF2V-PAF cells did not generate 
a CSL cell population (Fig. 4l). Conversely, ectopic expression of S33Y- $\beta$-catenin, a constitutively active form of $\beta$-catenin ${ }^{28}$, generated CSL cells (Fig. 4m), which was also suppressed by iCRT14 (Supplementary Fig. 8). It was previously shown that ectopic expression of $c-M y c$, a direct target of $\beta$-catenin ${ }^{29}$, reprogrammes epithelial and cancer cells into SC-like cells ${ }^{30}$; this prompted us to determine whether PAF-induced cell plasticity is due to $\beta$-catenin-mediated $c-M y c$ transactivation. We found that ectopic expression of c-Myc per se did not give rise to CSL cells from $76 \mathrm{NF} 2 \mathrm{~V}$ MECs. Instead, it induced the overall EMT (Supplementary Fig. 9), different from a previous study that suggested that EMT can give rise to breast CSL cells ${ }^{31}$. These results suggest that the $\mathrm{PAF}-\mathrm{Wnt} / \beta$-catenin signalling axis converts MECs into breast CSL cells.

PAF transactivation by stemness-associated factors. Next, we determined how $P A F$ expression is upregulated in breast cancer cells. We analysed the promoter sequence of $P A F$ to identify its transactivating transcription factors. Using MatInspector software (genomatix.de), we identified several transcription factors that may bind to $P A F$ promoter (Supplementary Table 1). Interestingly, we found several consensus binding sites for Oct1, Oct4, Nanog and TCF/lymphoid enhancer-binding factor 1 (LEFs) at $P A F^{\circ}$ s proximal promoter (Fig. 5a). Oct4, Sox2, Nanog and TCFs function as master regulators of stemness in embryonic $\mathrm{SCs}^{32,33}$ and their ectopic expression reprogrammes differentiated cells into a pluripotent SC lineage ${ }^{34}$. The results of recent studies also suggest that these stemness-associated factors are highly expressed in breast cancer and $\mathrm{CSCs}^{35-37}$. This evidence led us to determine whether Oct4 and Nanog transactivate PAF. Indeed, chromatin immunoprecipitation (ChIP) assays showed that Oct4 and Nanog occupied $P A F$ s proximal promoter in HER18 cells (Fig. 5b). We also found that PAF, Oct4 and Nanog were upregulated in breast cancer cell lines (Fig. 5c). Next, we determined whether Oct4 and Nanog are required for $P A F$ expression. Indeed, depletion of either endogenous Oct4 or Nanog downregulated PAF expression in HER18 cells (Fig. 5d,e) and other breast cancer cell lines (Fig. 5f). Conversely, ectopic expression of these stemness factors induced PAF expression in mouse embryonic fibroblasts and 293T cells, and induced slight expression in $76 \mathrm{NF} 2 \mathrm{~V}$ cells (Fig. $5 \mathrm{~g}$ ). These results suggest that Oct4 and Nanog transactivate $P A F$ in breast cancer cells.
PAF is required for maintaining breast cancer cell stemness. Given the PAF-induced conversion of MECs into CSL cells (see Fig. 4), we hypothesized that PAF is required for the maintenance of breast cancer cell stemness. It was previously shown that human breast cancer cell lines contain CSL cells ( 5\% of total cells), as assessed by CD24, CD44 and EpCAM expression ${ }^{13,25,38}$. Because of the high expression level of PAF in breast cancer cells (Fig. 1), we used loss-of-function approaches using lentiviruses that encode short hairpin RNA against green fluorescent protein (GFP) (control; shGFP) or PAF (shPAF) (Fig. 6a,b). We found that PAF depletion downregulated $\beta$-catenin target genes (AXIN2, $c-M y c$ and Cyclin D1) in breast cancer cells, recapitulating that $\mathrm{PAF}$ activates $\mathrm{Wnt} / \beta$-catenin signalling ${ }^{17}$ (Figs $3 g$ and $4 \mathrm{j}$ ). Next, we assessed the effects of PAF depletion on the quantity of CSL cells $\left(\mathrm{CD} 44^{\text {high }} \mathrm{CD} 24^{\text {negative }} \mathrm{EpCAM}^{\mathrm{low}}\right)$. Intriguingly, we found that PAF depletion or iCRT14 (inhibition of $\beta$-catenin-mediated gene transactivation) decreased the number of breast CSCs (Fig. 6c). Similarly, side population assays also showed that PAF depletion diminished the CSC population (Fig. 6d,e). In addition, iCRT14 treatment inhibits mammosphere formation of breast cancer cells (Supplementary Fig. 10). It is noteworthy that PAF knockdown and iCRT14 treatment did not affect breast cancer cell proliferation (data not shown). In addition, PAF depletion inhibited mammosphere formation in breast cancer cell lines (SUM159, HER18, MDAMB-435 and MDA-MB-453) (Fig. 6f-h). Subsequent dissociating and replating of cells from the primary mammospheres showed a similar inhibition of mammosphere formation in PAF-depleted cells (Fig. 6i,j), which was rescued by ectopic expression of PAF (Fig. 6k). Furthermore, we found that ectopic expression of S33Y- $\beta$-catenin rescues PAF depletion-induced inhibition of mammosphere formation (Fig. 6l,m). These results suggest that PAF-induced stemness maintenance is mediated by $\mathrm{Wnt} / \beta$-catenin signalling.

Next, we assessed the effects of PAF depletion on telomerase, a specific marker for self-renewing cells ${ }^{39}$. PAF depletion decreased telomerase activity (Fig. 6n), with downregulation of TERT, a catalytic subunit of telomerase, but not TERC, an RNA template of telomerase (Fig. 6o). Moreover, label-retaining cell (LRC) assays $^{40}$ showed that PAF depletion decreased the LRC population, which is considered the SC population (Fig. 6p,q). We also determined whether expression of PAF is enriched in the LRCs of HER18 breast cancer cells. Intriguingly, we found that

\footnotetext{
Figure 4 | Generation of CSC cells by PAF-Wnt signalling axis. (a,b) Increased mammosphere formation by PAF. 76NF2V-GFP or -PAF cells were cultured at low density (500 cells per $\mathrm{ml}$ in 6-well plate) in suspension condition. Primary mammosphere (at 10 days) were dissociated and re-plated for multiple propagations (12 days). (a) Phase-contrast images. (b) The number of mammospheres was quantified using plate counter. Scale bar, $100 \mu \mathrm{m}$.

(c) Expression of breast CSC markers in PAF-expressing MECs. 76NF2V-vector and -PAF cells were analysed for immunostaining with each antibody. Scale bars, $20 \mu \mathrm{m}$. (d) CD24 downregulation and CD44 upregulation by PAF ectopic expression. 76NF2V-vector and -PAF cells were analysed using FACS for CD24 and CD44 cell surface markers. PAF expression converted MEC properties from CD24 ${ }^{\text {high }}$ CD44 ${ }^{\text {low }}$ to CD24 ${ }^{\text {low }}$ CD44 ${ }^{\text {high }}$ in $76 N F 2 V-P A F$ epithelial cell-like cells (e) and CD24 ${ }^{\text {low }} C D 44^{\text {high }}$ in 76NF2V-PAF mesenchymal-like cells $(\mathbf{m})$. The representative results were shown $(\mathrm{N}=3)$. (e) Increased ALDH activity by PAF. 76NF2V-vector and -PAF cells were analysed for ALDH activity using FACS. MDA-MB-231 served as a positive control. The representative results were shown $(N=3)$. ( $(\mathbf{f}, \mathbf{g})$ Schematic diagram of PAF-induced cell plasticity. (f) Based on expression of three cell surface markers, CD44, CD24 and EpCAM, 76NF2V-control and -PAF cells can be sorted using FACS. (g) In hypothetical model, PAF expression converts MECs into SC-like cells that generate heterogeneous cell population. BE, basal epithelial cells; CSL, cancer SC-like cells; LE, luminal epithelial cells. (h,i) PAF-induced cell heterogeneity. Each group of cells (CSL, LE and BE) from 76NF2V-PAF cells was sorted using FACS and cultured for 6 days. Next, cells were reanalysed for cell properties using FACS (CD24, CD44 and EpCAM). The representative results were shown $(N=3)(\mathbf{h})$. Phase-contrast images (i). Scale bars, $50 \mu \mathrm{m}$. (j) Upregulation of AXIN2 by PAF. 76NF2V-control and -PAF cells were analysed for AXIN2 expression using quantitative reverse transcriptase-PCR (qRT-PCR). AXIN2 fold induction was normalized by GAPDH expression. Student's t-test; error bars = s.e.m. (k) Suppression of PAF-induced AXIN2 upregulation. 76NF2V-control (vector) and -PAF cells were treated with iCRT14 $(100 \mu \mathrm{M}$ for $24 \mathrm{~h})$ and analysed for AXIN2 expression. Student's $t$-test; error bars = s.e.m. (I) Suppression of PAF-induced generation of breast CSL cells by $\beta$-catenin inhibition. 76NF2V-control and -PAF cells were treated with iCRT14 (100 $\mu \mathrm{M}$ for $24 \mathrm{~h}$ ) and analysed using FACS for SC population (CD44 ${ }^{\text {high }} C D 24^{\text {negative }}$ EpCAM ${ }^{\text {low }}$ ). Dimethyl sulfoxide (DMSO) vehicle served as a negative control for iCRT14. Student's $t$-test; error bars $=$ s.e.m. $(\mathbf{m})$ Generation of CSL cells by active $\beta$-catenin. 76NF2V MECs stably expressing S33Y- $\beta$-catenin or c-Myc were analysed for CD24, CD44 and EpCAM expression using FACS. Student's $t$-test; error bars =s.e.m. ${ }^{\star} P<0.05 ; N<3$.
} 
PAF was relatively highly expressed in LRCs compared with in non-LRCs (Fig. 6r). These results suggest that PAF expression is upregulated in breast CSCs. Next, to determine the effects of $P A F$ knockout $(\mathrm{KO})$ on in vivo tumour formation, we generated $P A F$ KO MDA-MB-231 cell lines using the clustered regularly interspaced short palindromic repeat (CRISPR) gene targeting approach (Fig. 6s). PAF wild-type and $\mathrm{KO}$ cells were transplanted into the cleared mammary fat pads at a limiting dilution. Twelve weeks after transplantation, transplants with PAF KO cells had fewer outgrowths than did control cells, with a significant a

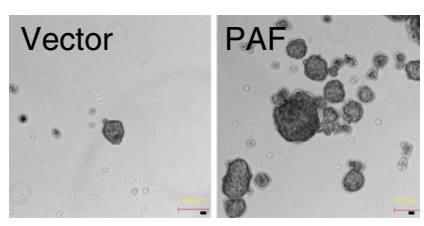

b
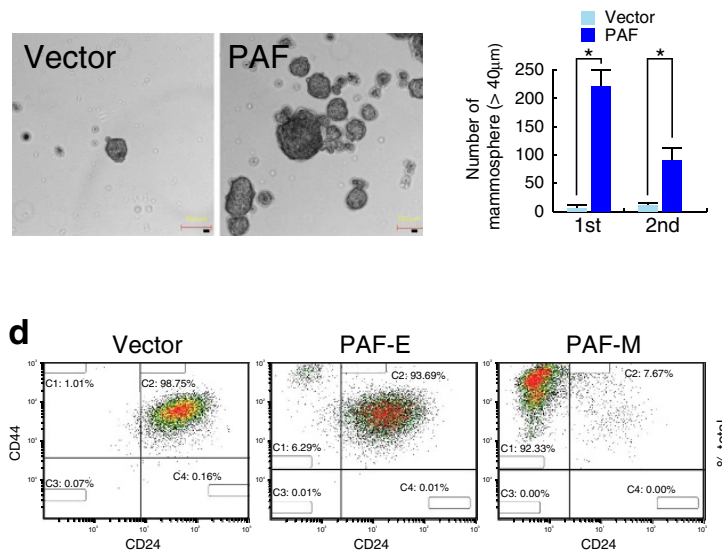
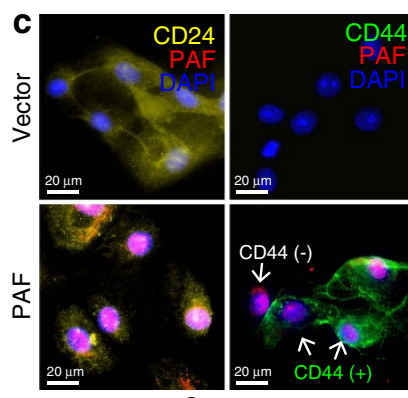

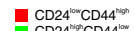

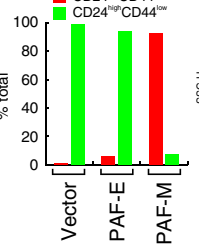

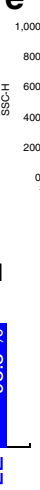
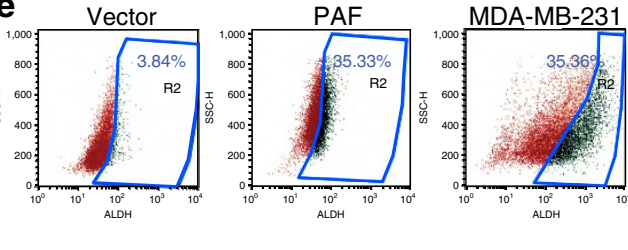

h
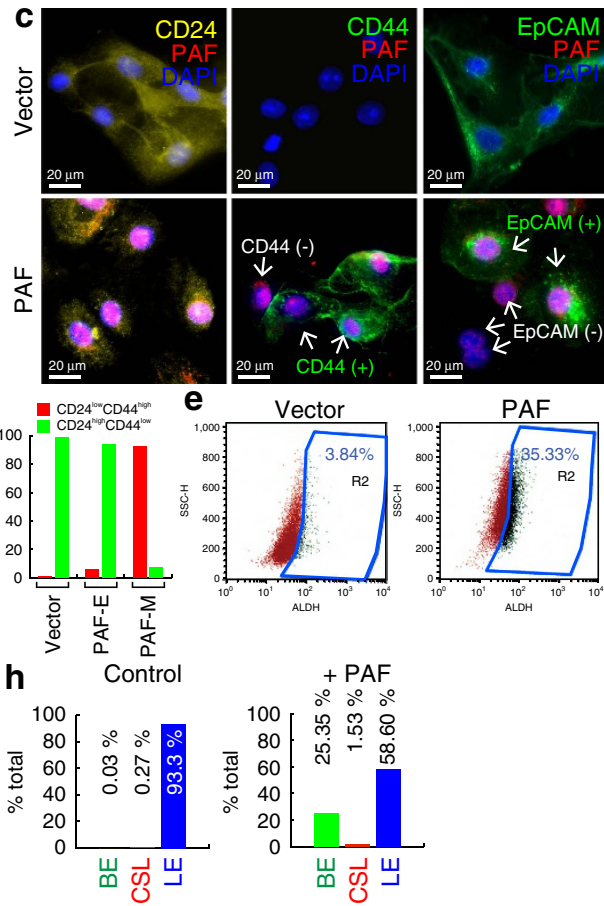

$\mathbf{f}$

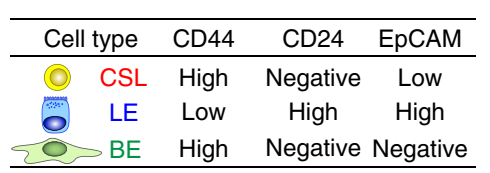

g

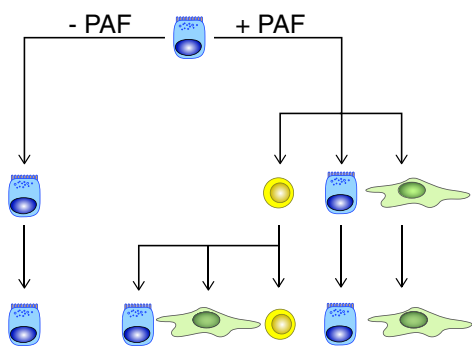

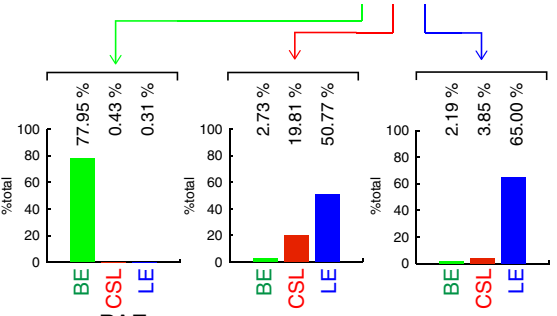
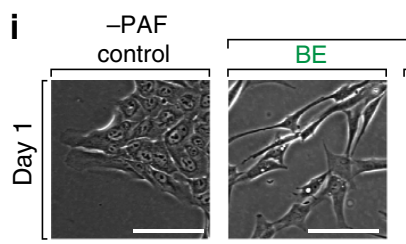

$+\mathrm{PAF}$
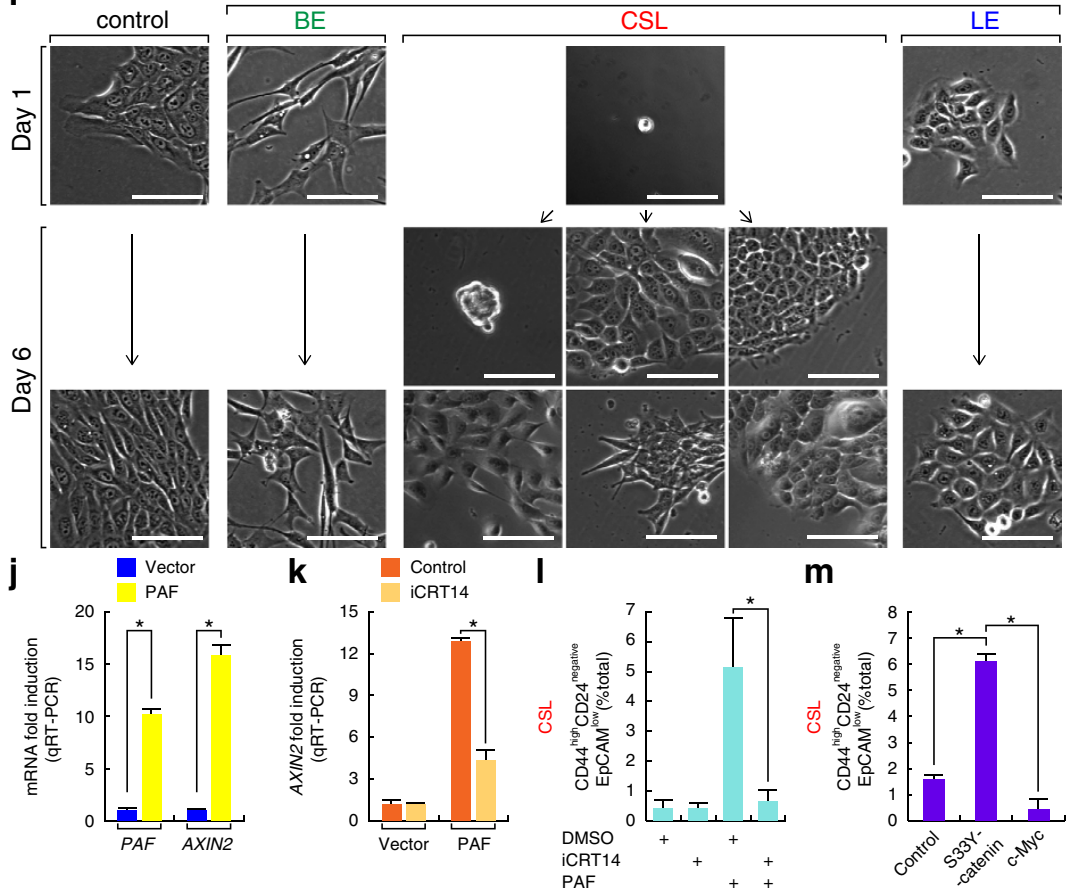
a

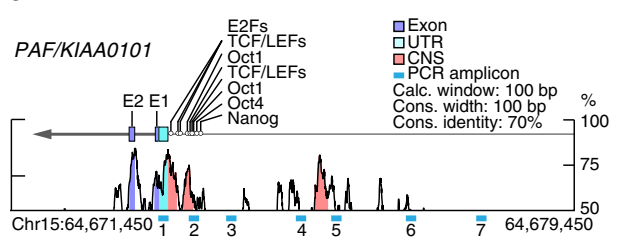

b

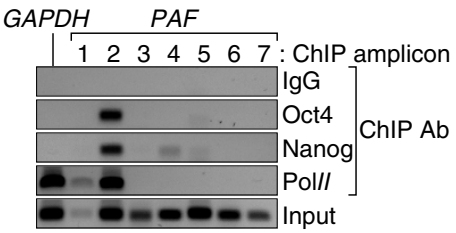

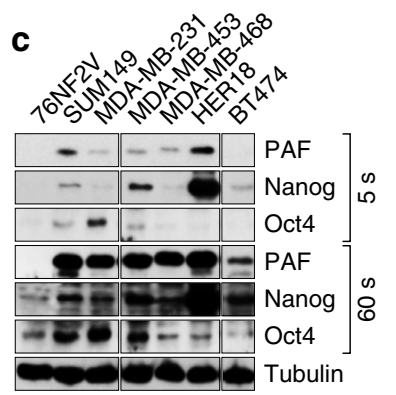

d

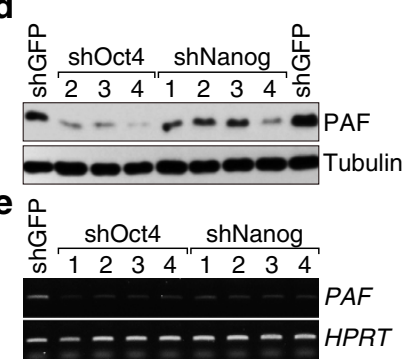

f

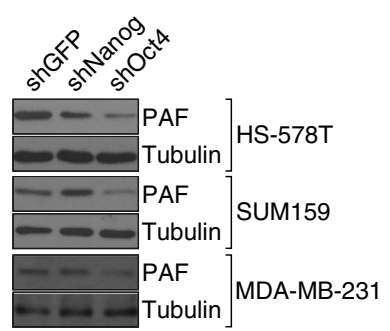

g

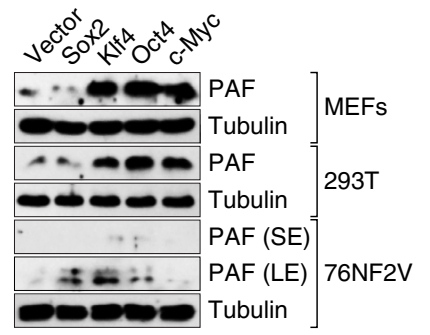

Figure 5 | PAF transactivation by Oct4 and Nanog. (a) PAF promoter analysis using VISTA genome browser. CNS, conserved non-coding sequence; TBE, TCF-binding elements; UTR, untranslated region. Green bars, PCR amplicons (1 7). (b) Oct4 and Nanog occupy PAF's proximal promoter. ChIP analysis of HER18. GAPDH promoter, a negative control for occupancy of Oct4 and Nanog; IgG, a negative control for IP; Input, 10\% were used for ChIP-PCR; RNA polymerase II (Pol II), a positive control for ChIP. (c) Expression analysis of PAF, Oct4 and Nanog. IB assays. LE, long exposure; SE, short exposure. (d-f) Depletion of either Oct4 or Nanog downregulates PAF expression. HER18 cells stably expressing short hairpin RNAs (shRNAs) were analysed for IB (d) and semi-quantitative RT-PCR (e). Other breast cancer cell lines were stably transduced with lentiviruses encoding shRNAs against Oct4 or Nanog. PAF expression was analysed by IB. (g) Ectopic expression of stemness-associated factors upregulates PAF expression. Each cell line was transfected with indicated plasmids. Twenty-four hours after transfection, cells were collected for IB analysis. MEFs, mouse embryonic fibroblasts.

decrease in the frequency of mammary gland-reconstituting cells of PAF KO cells ( 0.023 fold) (Fig. 6t). These results suggest that the PAF-Wnt signalling axis is required for the maintenance of breast cancer cell stemness.

Identification of clinical cancer drugs that target PAF. Because of specific expression of PAF in breast cancer cells, but not in the mammary gland (see Fig. 1), targeting PAF might specifically target breast cancer cells that express PAF. To this end, we screened 146 clinical cancer drugs (CCDs) to determine their effects on PAF expression (Supplementary Table 2). First, we treated MDA-MB-231 cells with 146 CCDs for $24 \mathrm{~h}$ and determined their effects on the PAF protein level. We identified 14 CCDs that significantly downregulate PAF protein. For the second round of screening, we treated HER18 cells with 14 selected CCDs and analysed the transcription level of PAF and AXIN2 by quantitative reverse transcriptase-PCR. Finally, we chose three CCDs (AZD1152-HPQA (52; aurora B kinase inhibitor), AZD7762 (55; Chk1 inhibitor) and NVP-AUY922 (82; Hsp90 inhibitor)) on the basis of their effects on the downregulation of both $P A F$ and AXIN2 expression (Fig. 7a). Next, we determined the effects of these three CCDs on the stemness of breast cancer cells by assessing ALDH activity. We found that treatment with AZD1152HPQA and NVP-AUY922 significantly reduced ALDH activity, as shown in PAF KO cells (Fig. 7b). Subsequent mammosphere assays showed that NVP-AUY922 remarkably inhibits mammosphere formation (Fig. 7c,d). In addition, NVP-AUY922 downregulates $\beta$-catenin target genes in breast cancer cell lines (Fig. 7e). These results suggest that NVP-AUY922 is a CCD that reduces breast cancer cell stemness by molecular targeting of PAF.

\section{Discussion}

We previously found that PAF is highly expressed in colorectal and pancreatic cancer, and hyperactivates the $\mathrm{Wnt} / \beta$-catenin and mitogen-activated protein kinase signalling pathways, which results in the initiation of tumorigenesis in mouse models ${ }^{17,41}$.
However, we found that PAF depletion or ectopic expression does not affect mitogen-activated protein kinase signalling activity in MECs and breast cancer cell lines (Supplementary Fig. 11). In addition, despite the role of PAF in DNA repair, PAF does not affect DNA damage response (Supplementary Fig. 12). These results suggest that PAF plays the distinct roles in breast cancer, unlike other cancer. Interestingly, PAF is not expressed in terminally differentiated cells but is specifically expressed in embryonic stem and intestinal $\mathrm{SCs}^{17}$, implying that it has roles in cell stemness. Interestingly, in silico analyses showed that PAF is also highly expressed in breast cancer cells (see Fig. 1), which led us to study its potential tumorigenic roles in breast cancer. Herein, we found that PAF induces the conversion of MECs into CSL cells via Wnt/ $\beta$-catenin signalling. In contrast, PAF depletion leads to the loss of stemness of breast cancer cells, which is required for the maintenance of breast cancer cell stemness (Fig. 7f). Furthermore, our drug-repurposing approaches identified the CCDs inhibiting breast cancer cell stemness by targeting PAF.

Deregulation of Wnt signalling is associated with various human cancers $^{42,43}$. In a mouse model, $M M T V$-driven ectopic Wnt-1 expression induced mammary hyperplasia and adenoma 44 However, the tumorigenic roles of Wnt signalling in human breast cancer have been controversial ${ }^{45,46}$. In recent times, it was suggested that $\mathrm{Wnt} / \beta$-catenin signalling deregulation is associated with triple-negative breast cancer ${ }^{47,48}$. Of note, unlike colorectal cancer, breast cancer cells exhibit infrequent genetic mutations of APC or $\beta$-catenin/CTNNB1 (refs 49,50), which implies that additional regulatory mechanisms of Wnt signalling exist. Hence, it is plausible that PAF overexpression is one of the regulatory mechanisms of Wnt signalling hyperactivation in breast cancer, including triple-negative breast cancer.

The traditional study of Wnt signalling in tumorigenesis has mainly focused on the effects of Wnt signalling hyperactivation on cell proliferation, which are mainly due to $\beta$-catenin-mediated transcriptional activation of $c-M y c^{29}$ and Cyclin D1 (ref. 51), which promotes cell proliferation. Despite the crucial roles of 

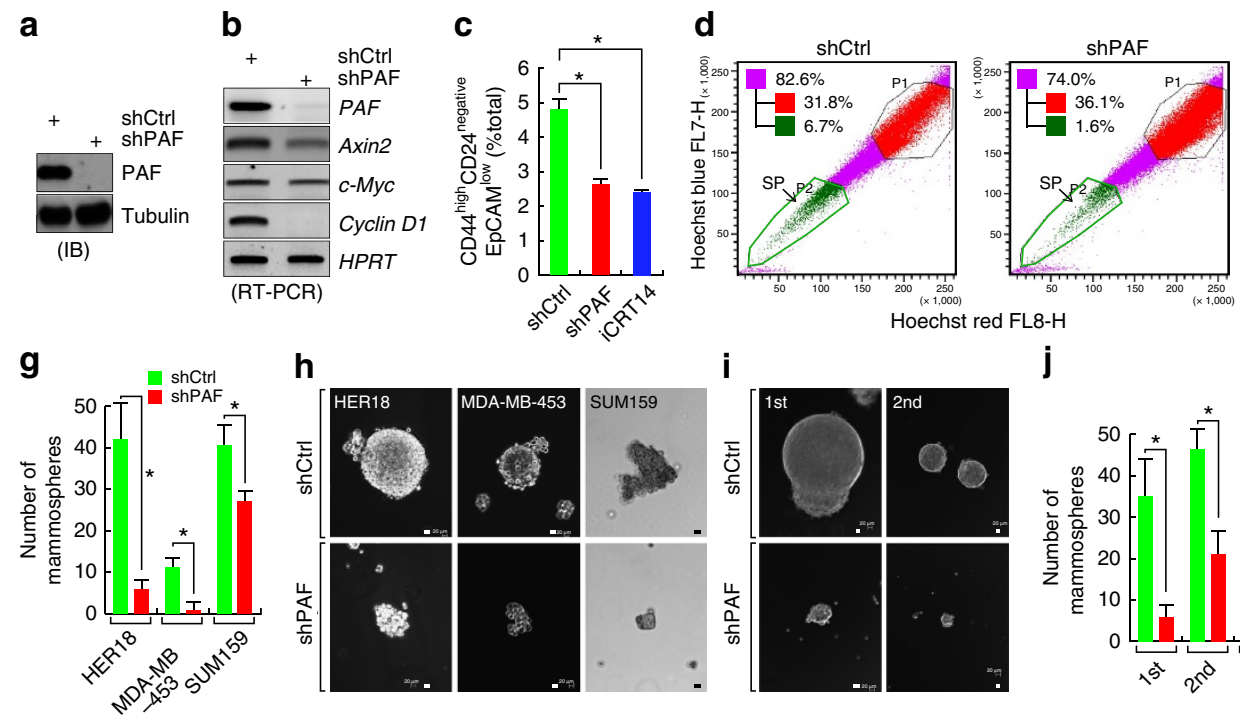

i
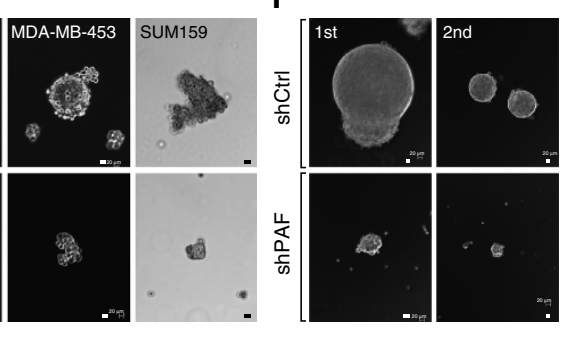

j
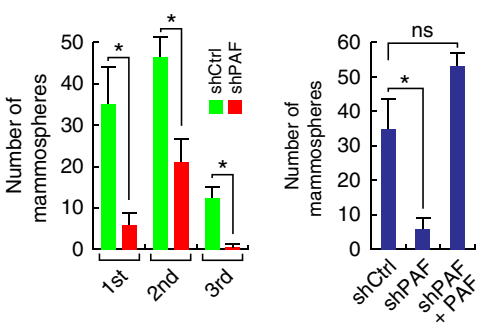

n
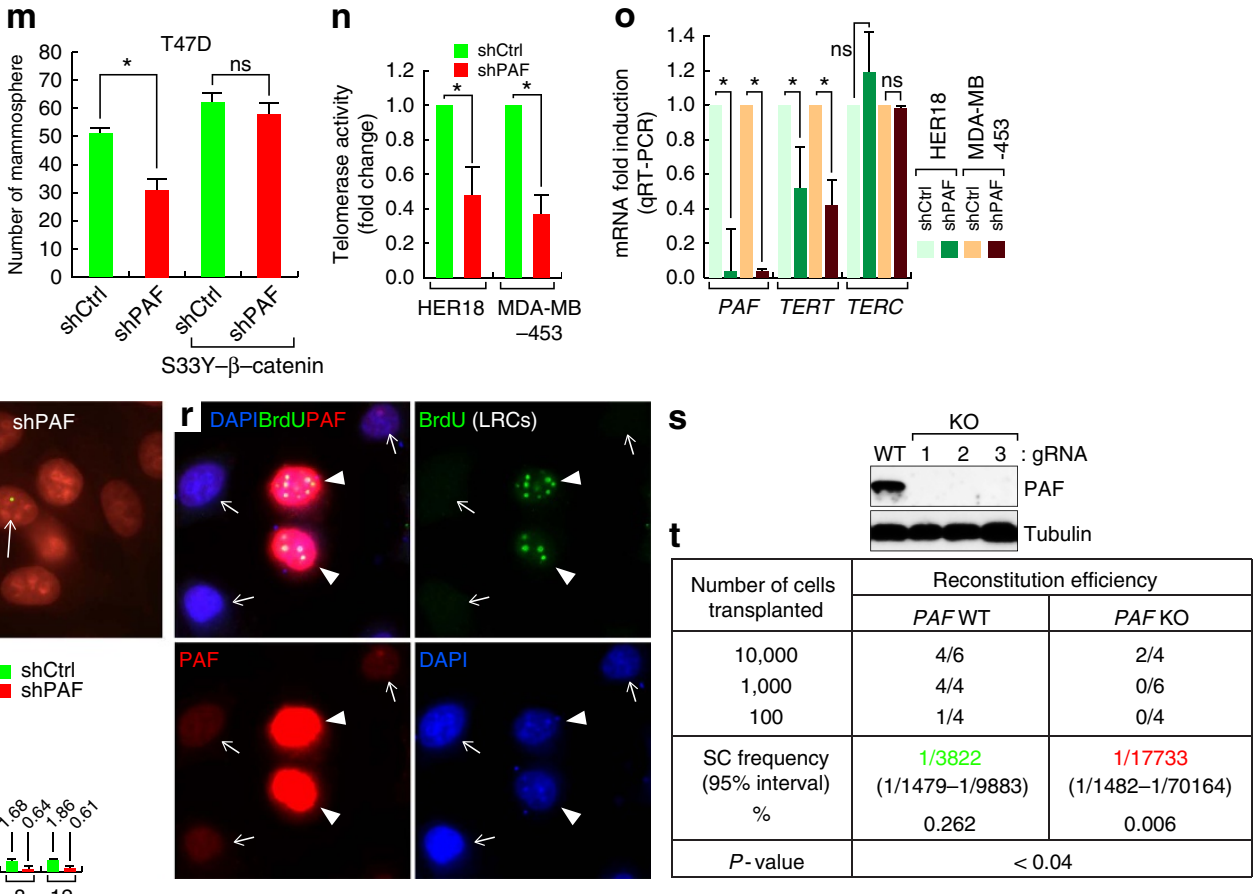

Figure 6 | PAF is required for breast CSC maintenance. (a,b) Depletion of endogenous PAF by shPAF. HER18 human breast cancer cells were transduced with lentivirus encoding shCtrl (control) or shPAF (PAF depletion) and selected with puromycin. PAF knockdown was confirmed using IB (a) and semiquantitative reverse transcriptase-PCR (RT-PCR) (b). Tubulin and HPRT served as internal controls. (c-e) PAF depletion decreases breast CSC population. HER18 cells (shCtrl (control), shPAF or iCRT14 treated) were analysed by flow cytometry and CSL population (CD44 ${ }^{\text {high }}$ CD24 ${ }^{\text {negative }}$ EpCAM ${ }^{\text {low }}$ ) was quantified (c). Side population analysis (d). Verapamil-treated samples served as negative controls (e). Student's t-test; error bars = s.e.m. (f) Depletion of endogenous PAF by short hairpin RNAs (shRNAs) in breast cancer cell lines. IB analysis. (g-j) Decrease in mammosphere formation by PAF depletion. Quantification of the number of mammospheres $(\mathbf{g})$ and phase-contrast images (h). Sequential mammosphere formation of HER18 cells (i,j). Of note, SUM159 and MDA-MB-453 cells did not form clear mammospheres. Student's $t$-test; error bars = s.e.m. Scale bars, $20 \mu m$. (k) Ectopic expression of PAF rescues inhibition of mammosphere formation by PAF depletion. HER18 cells were stably transduced by PAF and analysed for mammosphere formation. Student's $t$-test; error bars =s.e.m. (I,m) $\beta$-Catenin rescues PAF depletion-induced inhibition of mammosphere formation. shCtrl- and shPAF-transduced breast cancer cell lines were stably transfected with S33Y- $\beta$-catenin and assessed for mammosphere formation. Student's $t$-test; error bars = s.e.m.

(n) Decreased telomerase activity by PAF depletion. Cells (shCtrl versus shPAF) were analysed for telomerase activity using TRAPEZE RT kits. Student's $t$ test; error bars = s.e.m. (o) Downregulation of TERT by PAF depletion. Student's t-test; error bars, s.e.m. Quantitative reverse transcriptase-PCR (RT-PCR) analysis. Of note, TERC was not changed by PAF depletion. (p,q) Decrease in LRCs in PAF-depleted HER18 cells. HER18 cells were labelled with 5-bromodeoxyuridine (BrdU) for $24 \mathrm{~h}$ and analysed for LRCs by counting BrdU-positive cells ( $n$, microscopic images; 0 , graph). Of note, initially, equal

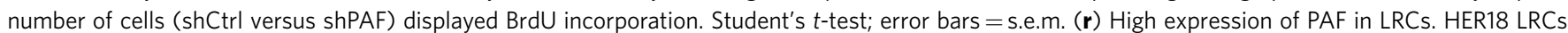
(2 months) were analysed for IF staining. Arrowheads: PAFigh and BrdUpositive cells; arrows: PAFlow and BrdUnegative cells. (s) Somatic KO of PAF by CRISPR. Wesrern blot (WB) analysis of MDA-MB-231 cells. (t) PAF KO inhibits stemness of breast cancer cells. MDA-MB-231 (PAF WT and KO) cells were transplanted into the cleared fat pad of immunocompromised mice. Twelve weeks after transplantation, tumour formation was assessed by extreme limiting dilution analysis. ${ }^{\star} P<0.05$; NS, not significant $(P \geq 0.05) ; N>3$. 
a
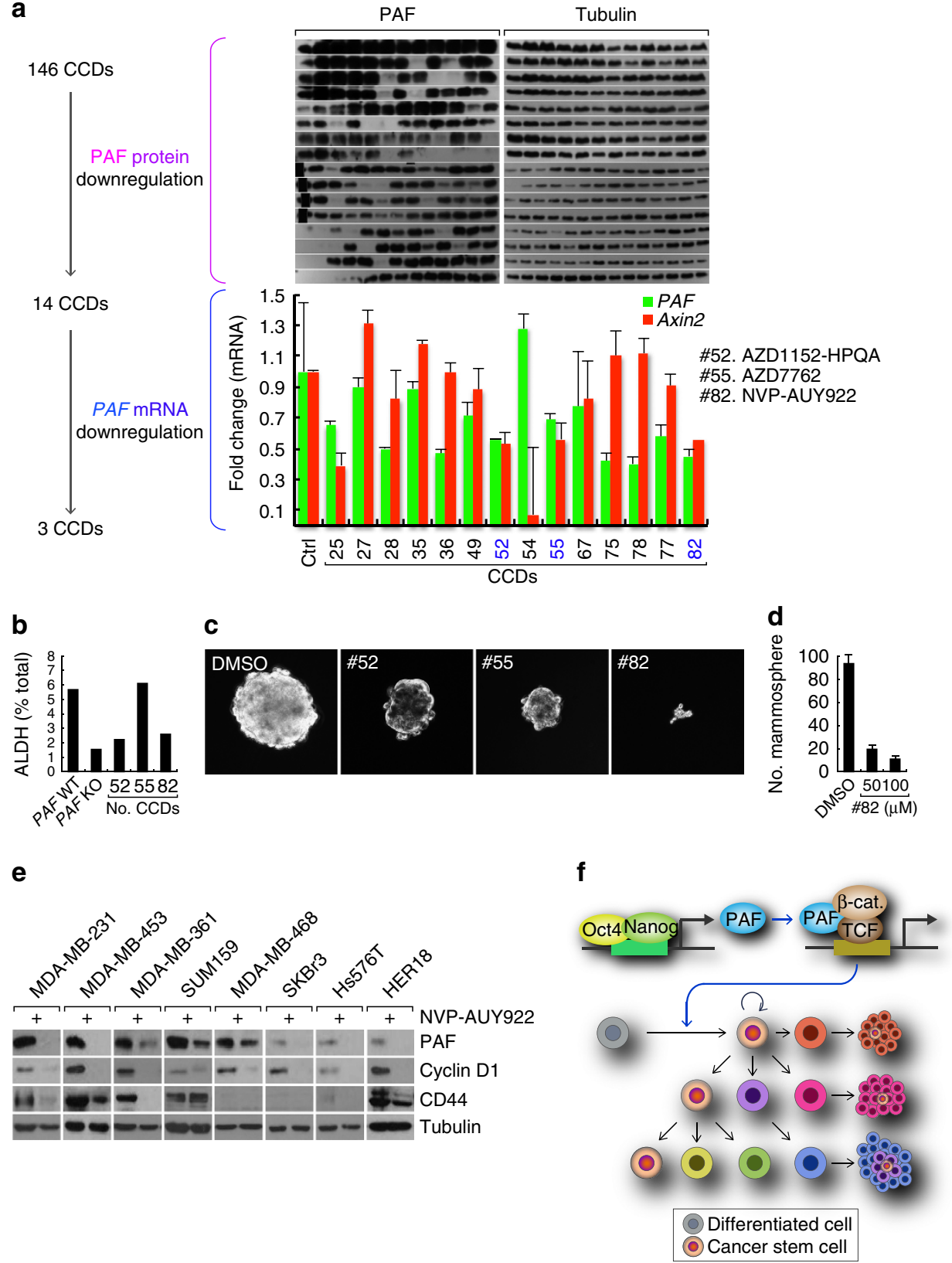

Figure 7 I Identification of clinical cancer drugs targeting PAF. (a) Total 146 CCDs were treated in HER 18 cells $(1 \mu \mathrm{M} ; 24 \mathrm{~h})$ for screening potential PAF inhibitors. Fourteen CCDs downregulating PAF protein are identified by IB assays. Next, among 14 CCDs, 3 CCDs (blue) were selected by their inhibitory effects on PAF and AXIN2 transcription using quantitative reverse transcriptase-PCR (qRT-PCR). Error bars = s.e.m. (b) Decreased ALDH activity by CCDs. HER18 cells were treated with three CCDs $(100 \mathrm{nM} ; 24 \mathrm{~h})$ and analysed for ALDH activity using FACS. HER18 PAF KO cells served as a negative control. Diethylaminobenzaldehyde (DEAB)-treated cells were also tested as a negative control (data not shown). (c,d) Decrease in mammosphere formation by NVP-AUY922. Phase-contrast images (c) and quantification of the number of mammosphere (d). Error bars =s.e.m. (e) Downregulation of $\beta$-catenin target genes by NVP-AUY922. Breast cancer cell lines were treated with NVP-AUY922 (100 nM, 36 h) and analysed by IB assays. (f) Illustration of working model: PAF-Wnt signalling axis in breast cancer cell stemness.

Wnt signalling in cell specification during embryogenesis, how cell fate is determined in tumorigenesis is poorly understood. It was shown that Wnt signalling increases the number of mammary SCs and progenitor cells ${ }^{52,53}$. In addition, Wnt signalling is required for the maintenance of mammary SCs ${ }^{54}$ and $\mathrm{Wnt} / \beta$-catenin signalling activation leads to the development of leukaemia SCs ${ }^{55}$. The results of these studies suggest that Wnt signalling hyperactivation enriches CSL cells. Intriguingly, $M M T V-W n t 1-$ or $-\Delta \beta$-catenin-derived mammary tumours contain both myo- and LE cell lineages, unlike other breast cancer mouse models, including $M M T V-N e u, M M T V-P y M T$ and $M M T V-H-R_{a s}{ }^{52,56}$. In addition, it was shown that Wntresponsive cells constitute various types of MECs during mammary development ${ }^{57}$. Thus, Wnt signalling might be associated with the generation of tumour cell heterogeneity. Nonetheless, its detailed molecular mechanisms remain ambiguous. Our findings reveal that the PAF-Wnt signalling axis converts MECs into CSL cells, which further develop cell heterogeneity. This may explain the molecular mechanism of the Wnt signalling-induced generation of tumour cell heterogeneity. 
In line with our findings, accumulating evidence suggests that various cells transform into CSL cells by hypoxia ${ }^{58}$, EMT ${ }^{31}$ or inflammation ${ }^{59}$. Spontaneous cell plasticity towards CSL cells was also observed ${ }^{60}$. Although $c-M y c$, a direct transcriptional target of $\beta$-catenin, was shown to trigger self-renewal reprogramming ${ }^{30}$, we observed that it induces EMT but not the generation of CSL cells (see Fig. 4l). EMT is the conversion of cell fate from epithelial cells to mesenchymal cells. Despite upregulation of EMT-associated genes and cell morphological change by PAF ectopic expression in MECs, we found that, unlike EMT, PAF induces the partial EMT, indicated by IF staining (see Fig. 2) and FACS analysis (see Fig. 4). This is also represented by the difference in CSL cell generation between $\mathrm{c}-\mathrm{Myc}$ and PAF. Although c-Myc induces the complete conversion of LE to BE (Supplementary Fig. 9), PAF expression generates cellular heterogeneity (LE, BE and CSL), which supports our model that PAF-induced cell plasticity generates CSL rather than EMT. These results suggest that other Wnt/ $\beta$-catenin target genes besides $c-M y c$ are associated with PAF-induced cell plasticity. Thus, identifying the key downstream target genes that initiate cell plasticity will be of great interest, which will elucidate the transcriptional circuits of cancer cell stemness.

Given that PAF is highly upregulated in breast cancer cells, it is likely to be that PAF-induced cell plasticity is a key pathologic process in maintaining breast CSCs. Intriguingly, $P A F$ ablation inhibits the stemness of breast cancer cells, which suggests that reversing cell plasticity by molecular targeting of PAF could be translated into a therapeutic intervention for breast cancer. To further develop methods for targeting PAF, we screened 146 CCDs on the basis of their effects on PAF expression. We found that AZD1152, AZD7762 and NVP-AUY922 markedly downregulated both protein and msessenger RNA levels of PAF and significantly reduced breast cancer cell stemness. AZD1152, an aurora $B$ kinase inhibitor ${ }^{61}$, induces radiation response in p53-deficient cancer cell including colorectal and pancreatic cancer cells $s^{62,63}$. AZD7762 enhances the activity of DNA-damage reagents in a p53-dependent manner ${ }^{64}$. In xenograft model, in combination with DNA damage reagents, AZD7762 increases cytotoxicity and inhibits tumour growth ${ }^{65,66}$. It was previously shown that NVP-AUY922 exhibits antitumour activity in breast cancer cells (Supplementary Fig. 13) ${ }^{67}$. Moreover, given the specific expression of PAF in the subset of cancer cells, but not in normal cells, targeting the PAF molecule may minimize its harmful effects on normal tissues. Of note, PAF KO mice are also viable $^{68}$, which further supports the benefit of molecular targeting of PAF. Thus, our results suggest that NVP-AUY922's effects on PAF downregulation can be translated into the development of targeted therapy against cancer cell stemness. Collectively, our findings reveal a previously unsuspected role of the PAF-Wnt signalling axis in maintaining cancer cell stemness by controlling cell plasticity.

\footnotetext{
Methods

Kaplan-Meier analysis. Kaplan-Meier analysis was performed using publicly available database (kmplot.com) ${ }^{69}$ with the following options: relapse-free survival; splitting patients by lower quartile split, judging from the numbers at risk at time; two probes for PAF/KIAA0101=202503_s_at and 211713_x_at; and without restricting analysis to subtypes.
}

Mammalian cell culture. Cell lines (MCF-7, T47D, MDA-MB-453, BT474, ZR75-1, MDA-MB-231, MDA-MB-468, HER18, SUM149, SUM159, 293T and HS578T) were purchased from American Type Culture Collection (ATCC) and maintained in DMEM medium containing $10 \%$ fetal bovine serum. $76 \mathrm{NF} 2 \mathrm{~V}$ and hMLE MEC cells, generous gifts from Drs Vimla Band and Li Ma, respectively, were cultured in in MEGM Bullet kit (Lonza). Mycoplasma contamination was examined using MycoAlert mycoplasma detection kit (Lonza). Lentiviruses and retroviruses encoding short hairpin RNAs (Sigma) or complementary DNA were stably transduced into target cells and selected using puromycin $\left(2 \mathrm{mg} \mathrm{ml}^{-1}\right)$.
For stable transfection, pcDNA3.1 mammalian expression plasmids (G418 for selection marker) were used. iCRT14, an inhibitor for $\beta$-catenin-TCF interaction was purchased from (Santa Cruz).

Constructs. All constructs were generated from cDNA or open reading frame sources via PCR and constructed into mammalian expression plasmids, retroviral or lentiviral vector plasmids (FLAG-pcDNA3.1, HA-pcDNA3.1, HA-pMSCV, FLAG-pMGIB and pCDH-CMV-MCS-EF1-Cop-EGFP). nt-PAF, S33Y- $\beta$-catenin mutants were constructed using PCR-based mutagenesis. Five different lentiviral plasmids encoding shPAFs (Sigma) were tested for depletion of endogenous PAF using immunoblotting. All constructs were verified using DNA sequencing.

Gene expression analysis. For RNA extraction, cells were processed using TRIzol reagent (Invitrogen). One microgram of RNA was used for reverse transcription using SuperScript II (Invitrogen). Next, cDNAs were used for gene expression analysis using quantitative reverse transcriptase-PCR. GAPDH or HPRT were used as internal controls for normalization. Fold induction was quantified using $2^{-\Delta \Delta C t}$ methods. The primer sequences can be found in Supplementary Table 3.

Immunoblotting. Whole-cell lysates of mammalian cells were prepared using NP40 lysis buffer (0.5\% NP-40, $1.5 \mathrm{mM} \mathrm{MgCl} 2,25 \mathrm{mM}$ HEPES, $150 \mathrm{mM} \mathrm{KCl,} 10 \%$ glycerol, $1 \mathrm{mM}$ phenylmethylsulfonyl fluoride, $12.7 \mathrm{mM}$ benzamidine $\mathrm{HCl}, 0.2 \mathrm{mM}$ aprotinin, $0.5 \mathrm{mM}$ leupeptin and $0.1 \mathrm{mM}$ pepstatin A) for $20 \mathrm{~min}$ at $4{ }^{\circ} \mathrm{C}$ followed by centrifugation (14,000 r.p.m. for $10 \mathrm{~min}$ ). Supernatants were denatured in $5 \times$ SDS sample buffer (200 mM Tris- $\mathrm{HCl}$ pH 6.8, 40\% glycerol, 8\% SDS, $200 \mathrm{mM}$ dithiothreitol and $0.08 \%$ bromophenol blue) at $95^{\circ} \mathrm{C}$ for $5 \mathrm{~min}$ followed by SDS-PAGE. For immunoblot blocking and antibody incubation, $0.1 \%$ non-fat dry milk in Tris-buffered saline and Tween-20 $(25 \mathrm{mM}$ Tris- $\mathrm{HCl} \mathrm{pH} 8.0,125 \mathrm{mM} \mathrm{NaCl}$ and $0.5 \%$ Tween-20) was used. SuperSignal West Pico and Femto reagents (Pierce) were used to detect horseradish peroxidase-conjugated secondary antibodies. The following antibodies were used for immunoblotting: PAF (Abcam (ab56773; 1:5,000) and Santa Cruz (FL-111; 1:2,000)), tubulin (Santa Cruz (A-6); 1:5,000), $\mathrm{N}$-cadherin (BD Biosciences (clone 32); 1:2,000), Fibronectin (BD Biosciences (clone 10); 1:2,000), E-cadherin (Cell Signaling (VU1D9); 1:1,000), Vimentin (BD Biosciences (RV202); 1:2,000) and FLAG (Sigma (M2); 1:5,000). The original immunoblotting images can be found in Supplementary Fig. 14.

Mammosphere and tumour sphere formation assay. 76NF2V human MECs were plated in triplicate in ultra-low attachment plates $(500$ cells per $\mathrm{ml})$ and grown in MEGM medium containing 1.3\% methylcellulose (Stem Cell Technologies) supplemented with $20 \mathrm{ng} \mathrm{ml}^{-1}$ epidermal growth factor, $10 \mathrm{ng} \mathrm{ml}^{-1}$ basic fibroblast growth factor (Sigma) and B27 (Gibco). In subsequent passage, spheres were dissociated into a single cell and plated (76NF2V: 500 cells per ml and breast cancer cell lines: 20,000 cells per ml). Sphere-forming activity was assessed 2 weeks after seeding. Size of spheres was quantified using and AxioVision software (Zeiss).

Migration and invasion assay. Cells were seeded in to 24-well cell culture inserts with $8 \mu \mathrm{m}$ pores (BD Falcon) coated with Matrigel. After $24 \mathrm{~h}$, the cells on the upper surface of the filters were removed with a cotton swab. For visualization, cells on lower filter surfaces were fixed and stained with $0.2 \%$ crystal violet. Invaded cells were analysed using Observer.Z1m microscope (Zeiss).

Transgenic animals. $i P A F$ mice previously generated were used ${ }^{17,41} . i P A F$ pups from two independent founder strains were used for analysis (all female mice; 1-2 months of age). PAF transgene expression was induced by doxycycline administration in the late generations crossed with C57BL/6 mice. Rosa26rtTA:iPAF or MMTV-rtTA:iPAF strains were administered doxycycline $\left(2 \mu \mathrm{g} \mathrm{ml}^{-1}\right.$ in $5 \%$ sucrose drinking water). $r t T A$ driver mice were purchased from The Jackson Laboratory. All mice were maintained and experiments were carried out according to institutional guidelines (MD Anderson Cancer Center) and Association for Assessment and Accreditation of Laboratory Animal Care International standards.

Xenograft assay. Nude female mice, aged 3 months, were divided into ten groups $\left(N=2\right.$ each) and inoculated with $1 \times 10^{7}$ cells of stable cell lines (MECs and MECs stably expressing PAF). After 8 weeks for adaptation, tumour development was assessed and immunohistochemistry was performed.

Flow cytometry and fluorescent-activated cell sorting. Single-cell suspensions of each cell line were counted and incubated with antibodies: CD24-PE (BD Pharmingen (ML5; 1:100)), CD44-APC (BD-Pharmingen (G44-26; 1:100)) and EpCAM-FITC (AbD Serotec (VU-1D9; 1:800)). ALDH enzymatic activity was assessed using ALDEFLUOR kit (Stem Cell Technologies) as per the manufacturer's protocol. Diethylaminobenzaldehyde-treated sample served as a negative control for gating. FACS analysis was performed using Becton Dickinson (BD). 
Immunohistochemistry and whole-mount staining. Murine mammary tissue samples were collected and fixed in 10\% formalin and processed for paraffin embedding. Sectioned samples were immunostained according to standard protocols: deparaffinization, blocking and incubation with primary and fluorescence-conjugated secondary antibodies. The following antibodies were used for immunohistochemistry: PAF (Abcam (ab56773; 1:250) and Santa Cruz Biotechnology (FL-111; 1:250)), CD44 (Abcam (IM7; 1:250)) and Ki67 (Abcam (SP6; 1:500)). For breast cancer tissue microarray, tissue microarray slides were purchased from Biomax and immunostained for PAF using anti-PAF antibody (Abcam (ab56773; 1:250)). Haematoxylin was used for nuclear counterstaining. For whole-mount mammary gland staining, mammary glands were dissected out and fixed on glass slide with Carnoy's solution (glacial acetic acid:chloroform:ethanol, 1:3:6) overnight at room temperature. Next, the glands were rehydrated and stained in aluminum carmine. The glands were then dehydrated, cleared with xylene and mounted. For breast cancer tissue analysis, breast cancer tissue microarray (Biomax; T085) was processed for nuclear antigen retrieval and the subsequent immunostaining.

ChIP assay. Cells were cross-linked with $1 \%$ formaldehyde for $15 \mathrm{~min}$ at room temperature. Formaldehyde was quenched by adding glycine (final concentration, $0.125 \mathrm{M})$. After washing the cells with cold $1 \times$ PBS solution, we harvested the cells with lysis buffer $\left(0.5 \% \mathrm{NP} 40\right.$, HEPES $25 \mathrm{mM}, \mathrm{KCl} 150 \mathrm{mM}, \mathrm{MgCl}_{2} 1.5 \mathrm{mM}, 10 \%$ glycerol and $\mathrm{KOH} \mathrm{pH} \mathrm{7.5)} \mathrm{containing} \mathrm{proteinase} \mathrm{inhibitors} \mathrm{and} \mathrm{further} \mathrm{incubated}$ the cells on ice for $15 \mathrm{~min}$. Cell lysates were centrifuged (5,000 r.p.m., $5 \mathrm{~min}$ ) and supernatants were discarded. Cell lysates were subjected to sonication with ChIPradioimmunoprecipitation assay lysis buffer (Tris $50 \mathrm{mM} \mathrm{pH} \mathrm{8.0,} \mathrm{NaCl} 150 \mathrm{mM}$, $0.1 \%$ SDS, $0.5 \%$ deoxycholate, $1 \%$ NP40 and EDTA $1 \mathrm{mM} ; 10$ times, $30 \mathrm{~s}$ on and $30 \mathrm{~s}$ off) and were centrifuged (13,200 r.p.m., $30 \mathrm{~min})$. Supernatant from lysates was immunoprecipitated with antibody overnight at $4{ }^{\circ} \mathrm{C}$ and was pulled down using protein A/G PLUS-Agarose (Santa Cruz Biotechnology) by centrifugation (3,400 r.p.m., $2 \mathrm{~min}$ ). Immunoprecipitates were further washed serially with ChIPradioimmunoprecipitation assay, high salt (Tris $50 \mathrm{mM} \mathrm{pH} 8.0, \mathrm{NaCl} 500 \mathrm{mM}$, $0.1 \%$ SDS, $0.5 \%$ deoxycholate, $1 \%$ NP40 and EDTA $1 \mathrm{mM}$ ), LiCl wash buffer (Tris $50 \mathrm{mM} \mathrm{pH} 8.0$, EDTA $1 \mathrm{mM}, \mathrm{LiCl} 250 \mathrm{mM}, 1 \% \mathrm{NP} 40$ and $0.5 \%$ deoxycholate) and Tris-EDTA buffer. Finally, immunoprecipitate cross-linking was reversed by incubation at $65^{\circ} \mathrm{C}$ overnight and immunoprecipitates were treated with RNase A and proteinase $\mathrm{K}$ to extract DNA. The following antibodies were used: RNA Polymerase II (EMD Millipore (CTD4H8; 1:100)), Oct4 (Cell Signaling (2750; 1:100) and Nanog (Cell Signaling (D73G4; 1:100)). ChIP amplicons (1-7) were detected via ChIP-PCR. Primer sequences can be found in Supplementary Table 3.

Somatic targeting of PAF alleles. KO cells were generated using the CRISPR. The lentiviral plasmid contains two expression cassettes, hSpCas9 and the chimeric guide RNA, where oligos were cloned, based on the protospacer adjacent motif on the target site, using standard cloning methodology generating lentiCRISPR. HEK293T cells were transfected with packaging plasmids including the lentiCRISPR, pCMV- $\triangle \mathrm{R} 8.2 \mathrm{dVPR}$ and pCMV-VSVG for lentiviral packaging. MDA-MB-231 breast cancer cell line was then transduced with lentiviruses and selected in puromycin for $72 \mathrm{~h}$. KO was confirmed by immunoblotting and genomic DNA sequencing. Guide RNA sequences were as follows: \#1: $5^{\prime}$-TGAA ACTGATGTCGAATTAG-3' ${ }^{\prime}$ \#2: $5^{\prime}$-GAGTTGGGCGCACGC AAACG-3 and \#3: 5-GGAGTTGGGCGCACGCAAAC-3'

Mammary fat pad transplantation assay. Limiting dilution of MDA-MB-231 cells $(P A F$ wild-type and $\mathrm{KO}$ ) resuspended in $20 \mu \mathrm{l}$ PBS was injected into the cleared mammary fat pads of 3-week-old NOD/SCID mice. After 12 week posttransplantation, mammary glands were harvested and positive reconstitution was determined. The frequency of SCs in the transplanted cell population was calculated using the Extreme Limiting Dilution Analysis Program (http://bioinf.wehi.edu.au/software/elda/index.html).

Statistical analysis. The Student's $t$-test was used for comparisons of two samples. Calculation of averages was performed using at least three biological replicates. $P$-values $<0.05$ were considered significant. Error bars in all figures indicate s.e.m.

\section{References}

1. Weissman, I. L., Anderson, D. J. \& Gage, F. Stem and progenitor cells: origins, phenotypes, lineage commitments, and transdifferentiations. Annu. Rev. Cell Dev. Biol. 17, 387-403 (2001).

2. Dezawa, M. et al. Bone marrow stromal cells generate muscle cells and repair muscle degeneration. Science 309, 314-317 (2005).

3. Jackson, K. A., Mi, T. \& Goodell, M. A. Hematopoietic potential of stem cells isolated from murine skeletal muscle. Proc. Natl Acad. Sci. USA 96, 14482-14486 (1999).

4. Cobaleda, C., Jochum, W. \& Busslinger, M. Conversion of mature B cells into $\mathrm{T}$ cells by dedifferentiation to uncommitted progenitors. Nature 449, 473-477 (2007).
5. Heyworth, C., Pearson, S., May, G. \& Enver, T. Transcription factor-mediated lineage switching reveals plasticity in primary committed progenitor cells. EMBO J. 21, 3770-3781 (2002).

6. Caiazzo, M. et al. Direct generation of functional dopaminergic neurons from mouse and human fibroblasts. Nature 476, 224-227 (2011).

7. Pang, Z. P. et al. Induction of human neuronal cells by defined transcription factors. Nature 476, 220-223 (2011).

8. Sekiya, S. \& Suzuki, A. Direct conversion of mouse fibroblasts to hepatocyte-like cells by defined factors. Nature 475, 390-393 (2011).

9. Dor, Y., Brown, J., Martinez, O. I. \& Melton, D. A. Adult pancreatic beta-cells are formed by self-duplication rather than stem-cell differentiation. Nature $\mathbf{4 2 9}$, 41-46 (2004).

10. Thorel, F. et al. Conversion of adult pancreatic alpha-cells to beta-cells after extreme beta-cell loss. Nature 464, 1149-1154 (2010).

11. Zhou, Q., Brown, J., Kanarek, A., Rajagopal, J. \& Melton, D. A. In vivo reprogramming of adult pancreatic exocrine cells to beta-cells. Nature 455, 627-632 (2008).

12. Dean, M., Fojo, T. \& Bates, S. Tumour stem cells and drug resistance. Nat. Rev. Cancer 5, 275-284 (2005).

13. Visvader, J. E. \& Lindeman, G. J. Cancer stem cells in solid tumours: accumulating evidence and unresolved questions. Nat. Rev. Cancer 8, 755-768 (2008).

14. Magee, J. A., Piskounova, E. \& Morrison, S. J. Cancer stem cells: impact, heterogeneity, and uncertainty. Cancer Cell 21, 283-296 (2012).

15. Yu, P. et al. p15(PAF), a novel PCNA associated factor with increased expression in tumor tissues. Oncogene 20, 484-489 (2001).

16. Povlsen, L. K. et al. Systems-wide analysis of ubiquitylation dynamics reveals a key role for PAF15 ubiquitylation in DNA-damage bypass. Nat. Cell Biol. 14, 1089-1098 (2012).

17. Jung, H. Y. et al. PAF and EZH2 induce Wnt/beta-catenin signaling hyperactivation. Mol. Cell 52, 193-205 (2013).

18. Liu, Y. et al. Multiple functions of human papillomavirus type 16 E6 contribute to the immortalization of mammary epithelial cells. J. Virol. 73, 7297-7307 (1999).

19. Jun, S. et al. PAF-mediated MAPK signaling hyperactivation via LAMTOR3 induces pancreatic tumorigenesis. Cell Rep. 5, 314-322 (2013).

20. Wielenga, V. J. et al. Expression of CD44 in Apc and Tcf mutant mice implies regulation by the WNT pathway. Am. J. Pathol. 154, 515-523 (1999).

21. Elenbaas, B. et al. Human breast cancer cells generated by oncogenic transformation of primary mammary epithelial cells. Genes Dev. 15, 50-65 (2001).

22. Al-Hajj, M., Wicha, M. S., Benito-Hernandez, A., Morrison, S. J. \& Clarke, M. F. Prospective identification of tumorigenic breast cancer cells. Proc. Natl Acad. Sci. USA 100, 3983-3988 (2003).

23. Band, V., Zajchowski, D., Kulesa, V. \& Sager, R. Human papilloma virus DNAs immortalize normal human mammary epithelial cells and reduce their growth factor requirements. Proc. Natl Acad. Sci. USA 87, 463-467 (1990).

24. Ginestier, C. et al. ALDH1 is a marker of normal and malignant human mammary stem cells and a predictor of poor clinical outcome. Cell Stem Cell $\mathbf{1}$, 555-567 (2007).

25. Gupta, P. B. et al. Stochastic state transitions give rise to phenotypic equilibrium in populations of cancer cells. Cell 146, 633-644 (2011).

26. Lustig, B. et al. Negative feedback loop of Wnt signaling through upregulation of conductin/axin2 in colorectal and liver tumors. Mol. Cell. Biol. 22, 1184-1193 (2002).

27. Gonsalves, F. C. et al. An RNAi-based chemical genetic screen identifies three small-molecule inhibitors of the Wnt/wingless signaling pathway. Proc. Natl Acad. Sci. USA 108, 5954-5963 (2011).

28. Kolligs, F. T., Hu, G., Dang, C. V. \& Fearon, E. R. Neoplastic transformation of RK3E by mutant beta-catenin requires deregulation of Tcf/Lef transcription but not activation of c-myc expression. Mol. Cell. Biol. 19, 5696-5706 (1999).

29. He, T. C. et al. Identification of c-MYC as a target of the APC pathway. Science 281, 1509-1512 (1998).

30. Wong, D. J. et al. Module map of stem cell genes guides creation of epithelial cancer stem cells. Cell Stem Cell 2, 333-344 (2008).

31. Mani, S. A. et al. The epithelial-mesenchymal transition generates cells with properties of stem cells. Cell 133, 704-715 (2008).

32. Jaenisch, R. \& Young, R. Stem cells, the molecular circuitry of pluripotency and nuclear reprogramming. Cell 132, 567-582 (2008).

33. Loh, Y. H. et al. The Oct4 and Nanog transcription network regulates pluripotency in mouse embryonic stem cells. Nat. Genet. 38, 431-440 (2006).

34. Okita, K., Ichisaka, T. \& Yamanaka, S. Generation of germline-competent induced pluripotent stem cells. Nature 448, 313-317 (2007).

35. Leis, O. et al. Sox 2 expression in breast tumours and activation in breast cancer stem cells. Oncogene 31, 1354-1365 (2012).

36. Ponti, D. et al. Isolation and in vitro propagation of tumorigenic breast cancer cells with stem/progenitor cell properties. Cancer Res. 65, 5506-5511 (2005). 
37. Patel, S. A. et al. Delineation of breast cancer cell hierarchy identifies the subset responsible for dormancy. Sci. Rep. 2, 906 (2012).

38. Fillmore, C. M. \& Kuperwasser, C. Human breast cancer cell lines contain stem-like cells that self-renew, give rise to phenotypically diverse progeny and survive chemotherapy. Breast Cancer Res. 10, R25 (2008).

39. Hiyama, E. \& Hiyama, K. Telomere and telomerase in stem cells. Br. J. Cancer 96, 1020-1024 (2007).

40. Buczacki, S. J. et al. Intestinal label-retaining cells are secretory precursors expressing Lgr5. Nature 495, 65-69 (2013).

41. Jun, S. et al. PAF-mediated MAPK signaling hyperactivation via LAMTOR3 induces pancreatic tumorigenesis. Cell Rep. 5, 314-322 (2013).

42. Polakis, P. Wnt signaling and cancer. Genes Dev. 14, 1837-1851 (2000).

43. Clevers, H. \& Nusse, R. Wnt/beta-catenin signaling and disease. Cell 149, 1192-1205 (2012).

44. Tsukamoto, A. S., Grosschedl, R., Guzman, R. C., Parslow, T. \& Varmus, H. E. Expression of the int-1 gene in transgenic mice is associated with mammary gland hyperplasia and adenocarcinomas in male and female mice. Cell 55, 619-625 (1988)

45. Dolled-Filhart, M. et al. Quantitative in situ analysis of beta-catenin expression in breast cancer shows decreased expression is associated with poor outcome. Cancer Res. 66, 5487-5494 (2006).

46. Lin, S. Y. et al. Beta-catenin, a novel prognostic marker for breast cancer: its roles in cyclin D1 expression and cancer progression. Proc. Natl Acad. Sci. USA 97, 4262-4266 (2000).

47. Khramtsov, A. I. et al. Wnt/beta-catenin pathway activation is enriched in basal-like breast cancers and predicts poor outcome. Am. J. Pathol. 176, 2911-2920 (2010)

48. Geyer, F. C. et al. beta-Catenin pathway activation in breast cancer is associated with triple-negative phenotype but not with CTNNB1 mutation. Mod. Pathol. 24, 209-231 (2011).

49. Hayes, M. J., Thomas, D., Emmons, A., Giordano, T. J. \& Kleer, C. G. Genetic changes of Wnt pathway genes are common events in metaplastic carcinomas of the breast. Clin. Cancer Res. 14, 4038-4044 (2008).

50. Zardawi, S. J., O’Toole, S. A., Sutherland, R. L. \& Musgrove, E. A. Dysregulation of Hedgehog, Wnt and Notch signalling pathways in breast cancer. Histol. Histopathol. 24, 385-398 (2009).

51. Shtutman, M. et al. The cyclin D1 gene is a target of the beta-catenin/LEF-1 pathway. Proc. Natl Acad. Sci. USA 96, 5522-5527 (1999).

52. Liu, B. Y., McDermott, S. P., Khwaja, S. S. \& Alexander, C. M. The transforming activity of Wnt effectors correlates with their ability to induce the accumulation of mammary progenitor cells. Proc. Natl Acad. Sci. USA 101, 4158-4163 (2004).

53. Kessenbrock, K. et al. A role for matrix metalloproteinases in regulating mammary stem cell function via the Wnt signaling pathway. Cell Stem Cell 13, 300-313 (2013)

54. Zeng, Y. A. \& Nusse, R. Wnt proteins are self-renewal factors for mammary stem cells and promote their long-term expansion in culture. Cell Stem Cell 6, 568-577 (2010).

55. Wang, Y. et al. The Wnt/beta-catenin pathway is required for the development of leukemia stem cells in AML. Science 327, 1650-1653 (2010).

56. Rosner, A. et al. Pathway pathology: histological differences between ErbB/Ras and Wnt pathway transgenic mammary tumors. Am. J. Pathol. 161, 1087-1097 (2002).

57. van Amerongen, R., Bowman, A. N. \& Nusse, R. Developmental stage and time dictate the fate of Wnt/beta-catenin-responsive stem cells in the mammary gland. Cell Stem Cell 11, 387-400 (2012).

58. Das, B. et al. Hypoxia enhances tumor stemness by increasing the invasive and tumorigenic side population fraction. Stem Cells 26, 1818-1830 (2008).

59. Iliopoulos, D., Hirsch, H. A. \& Struhl, K. An epigenetic switch involving NF-kappaB, Lin28, Let-7 MicroRNA, and IL6 links inflammation to cell transformation. Cell 139, 693-706 (2009).

60. Chaffer, C. L. et al. Normal and neoplastic nonstem cells can spontaneously convert to a stem-like state. Proc. Natl Acad. Sci. USA 108, 7950-7955 (2011).

61. Mortlock, A. A. et al. Discovery, synthesis, and in vivo activity of a new class of pyrazoloquinazolines as selective inhibitors of aurora B kinase. J. Med. Chem. 50, 2213-2224 (2007).
62. Tao, Y. et al. Enhancement of radiation response in p53-deficient cancer cells by the Aurora-B kinase inhibitor AZD1152. Oncogene 27, 3244-3255 (2008).

63. Azzariti, A. et al. Aurora B kinase inhibitor AZD1152: determinants of action and ability to enhance chemotherapeutics effectiveness in pancreatic and colon cancer. Br. J. Cancer 104, 769-780 (2011).

64. Lyne, P. D. et al. Identification of compounds with nanomolar binding affinity for checkpoint kinase-1 using knowledge-based virtual screening. J. Med. Chem. 47, 1962-1968 (2004).

65. Zabludoff, S. D. et al. AZD7762, a novel checkpoint kinase inhibitor, drives checkpoint abrogation and potentiates DNA-targeted therapies. Mol. Cancer Ther. 7, 2955-2966 (2008).

66. Mitchell, J. B. et al. In vitro and in vivo radiation sensitization of human tumor cells by a novel checkpoint kinase inhibitor, AZD7762. Clin. Cancer Res. 16, 2076-2084 (2010).

67. Jensen, M. R. et al. NVP-AUY922: a small molecule HSP90 inhibitor with potent antitumor activity in preclinical breast cancer models. Breast Cancer Res. 10, R33 (2008)

68. Amrani, Y. M. et al. The Paf oncogene is essential for hematopoietic stem cell function and development. J. Exp. Med. 208, 1757-1765 (2011).

69. Gyorffy, B. et al. An online survival analysis tool to rapidly assess the effect of 22,277 genes on breast cancer prognosis using microarray data of 1,809 patients. Breast Cancer Res. Treat. 123, 725-731 (2010)

\section{Acknowledgements}

We thank Esther M. Lien and Dana Richardson for technical assistance. This work was supported by the Cancer Prevention and Research Institute of Texas (RP140563), the National Institutes of Health (NCI R01 CA193297-01), the Department of Defense Peer Reviewed Cancer Research Program (CA140572), the Duncan Family Institute Research Program, the University Cancer Foundation (IRG-08-061-01), the Center for Stem Cell and Developmental Biology (The University of Texas MD Anderson Cancer Center), an Institutional Research Grant (MD Anderson Cancer Center), a New Faculty Award (MD Anderson Cancer Center Support Grant), a Metastasis Research Center Grant (MD Anderson Cancer Center), SPORE in ovarian cancer (P50 CA83639), Mike Hogg Award, the Research Training Award from the CPRIT (RP140106 to A.S.) and the Financial Supporting Project of Long-term Overseas Dispatch of Pusan National University Tenure-track Faculty (to B.J.P.). The Flow Cytometry and Cellular Imaging Facility is supported by the NIH through the MD Anderson Cancer Center Support Grant (CA016672).

\section{Author contributions}

X.W., Y.S.J. and J.-I.P. conceived the experiments. X.W., Y.S.J., S.J., S.L., W.W., Y.S.O., A.S. and J.-I.P. performed the experiments. W.W., K.K. and S.H.L. provided the reagents. X.W., B.J.P., J.C. and J.-I.P. analysed the data. J.-I.P. wrote the manuscript.

\section{Additional information}

Supplementary Information accompanies this paper at http://www.nature.com/ naturecommunications

Competing financial interests: The authors declare no competing financial interests.

Reprints and permission information is available online at http://npg.nature.com/ reprintsandpermissions.

How to cite this article: Wang, X. et al. PAF-Wnt signalling-induced cell plasticity is required for maintenance of breast cancer cell stemness. Nat. Commun. 7:10633 doi: $10.1038 /$ ncomms10633 (2016).

This work is licensed under a Creative Commons Attribution 4.0 International License. The images or other third party material in this article are included in the article's Creative Commons license, unless indicated otherwise in the credit line; if the material is not included under the Creative Commons license, users will need to obtain permission from the license holder to reproduce the material To view a copy of this license, visit http://creativecommons.org/licenses/by/4.0/ 